\title{
Titanium Dioxide Nanoparticles Induce Mitochondrial Dynamic Imbalance and Damage in HT22 Cells
}

\author{
Han Zhao, ${ }^{1,2}$ Liang Chen, ${ }^{1}$ Guisheng Zhong, ${ }^{3}$ Yina Huang, ${ }^{1,2}$ Xulai Zhang, ${ }^{4}$ Cenfeng Chu, ${ }^{3}$ \\ Lin Chen $(1),{ }^{1,2}$ and Ming Wang $(1)^{1,2}$ \\ ${ }^{1}$ Hefei National Laboratory for Physical Sciences at the Microscale and School of Life Sciences, University of Science and Technology \\ of China, Hefei 230027, China \\ ${ }^{2}$ Auditory Research Laboratory, University of Science and Technology of China, Hefei 230027, China \\ ${ }^{3}$ iHuman Institute, ShanghaiTech University, Shanghai 201210, China \\ ${ }^{4}$ Anhui Mental Health Center, Anhui Province, Hefei 230022, China
}

Correspondence should be addressed to Lin Chen; linchen@ustc.edu.cn and Ming Wang; wming@ustc.edu.cn

Received 28 August 2018; Revised 9 January 2019; Accepted 16 January 2019; Published 30 April 2019

Academic Editor: Enrico Bergamaschi

Copyright (c) 2019 Han Zhao et al. This is an open access article distributed under the Creative Commons Attribution License, which permits unrestricted use, distribution, and reproduction in any medium, provided the original work is properly cited.

\begin{abstract}
Mitochondria, as dynamic organelles, are precisely regulated by fusion and fission. The dynamic balance of fusion and fission controls mitochondrial morphology and their subcellular location and function. Exposure to titanium dioxide nanoparticles $\left(\mathrm{TiO}_{2} \mathrm{NPs}\right)$ may cause serious health problems. However, how $\mathrm{TiO}_{2} \mathrm{NPs}$ affect the mitochondrial dynamics remains unclear. In the present study, we investigated the changes of mitochondrial dynamics in the $\mathrm{TiO}_{2} \mathrm{NPs}$-treated HT22 cells by confocal and stimulated emission depletion (STED) microscopy. The confocal images demonstrated obvious changes in the average length and density of the mitochondria after $\mathrm{TiO}_{2}$ NPs treatment, while STED images further obtained the nanoscale submitochondrial structures of the mitochondria under $\mathrm{TiO}_{2} \mathrm{NPs}$ insult. The fluorescence intensity distributions suggested that mitochondria fragmented in the $\mathrm{TiO}_{2} \mathrm{NPs}$-treated cells. $\mathrm{TiO}_{2} \mathrm{NPs}$ treatment caused mitochondrial dynamic imbalance due to the imbalanced expression of dynamin-related protein 1 (Drp1) and optic atrophy 1 (Opa1). Furthermore, we examined the levels of oxidative stress and mitochondrial membrane potential (MMP) and the generation of adenosine triphosphate (ATP), which revealed the damage of mitochondria under $\mathrm{TiO}_{2}$ NPs exposure. Meanwhile, the significant changes of expressions of B-cell lymphoma

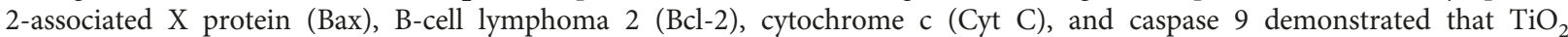
NPs treatment activated the mitochondrial-related apoptosis pathway. These cellular events can be largely prevented via cell incubation with mitoTEMPO, a mitochondria-targeted superoxide scavenger. Our results confirm that TiO $\mathrm{NPs}_{2}$ targeted the mitochondria, inducing mitochondrial dynamic imbalance and damage in HT22 cells. Our study provides an insightful understanding of the mechanisms underlying $\mathrm{TiO}_{2} \mathrm{NPs}$ cytotoxicity.
\end{abstract}

\section{Introduction}

Titanium dioxide nanoparticles $\left(\mathrm{TiO}_{2}\right.$ NPs) have been increasingly used in various applications, such as food additives, sunscreen, cosmetics, toothpastes, and environmental decontamination [1-5]. Studies estimated that annual $\mathrm{TiO}_{2}$ NPs production was between 5000 and 6400 tons $[6,7]$. The expanding usage and the large amounts of $\mathrm{TiO}_{2} \mathrm{NPs}$ being produced raise the risk of environmental exposure. $\mathrm{TiO}_{2}$ NPs may cause serious health problems. For example, $\mathrm{TiO}_{2} \mathrm{NPs}$ were reported to cause a clear epigenetic alteration in lung fibroblasts [8]. Even gestational exposure to $\mathrm{TiO}_{2} \mathrm{NPs}$ impaired placentation [9]. Previous studies indicated that $\mathrm{TiO}_{2}$ NPs were able to target the central nervous system and impair the brain [10-14]. Our own work has demonstrated that $\mathrm{TiO}_{2}$ NPs exposure could affect hippocampal synaptic plasticity, which indicated that hippocampus neurons were susceptible to $\mathrm{TiO}_{2} \mathrm{NPs}$ exposure [15]. It is worth noting that oxidative stress, which is caused by excessive accumulation of reactive oxygen species (ROS), is the main reason for the negative health effects of $\mathrm{TiO}_{2} \mathrm{NPs}[16,17]$. Given the fact that mitochondria are the major source of 
ROS in neurons, mitoTEMPO is specifically targeted to mitochondria and subsequently eliminates mitochondrial superoxide and protects mitochondrial function $[18,19]$.

Mitochondrial morphology is dynamically regulated by an opposing balance of fusion and fission [20]. In mammalian cells, mitochondrial fusion is mainly regulated by the inner mitochondrial membrane protein, optic atrophy 1 (Opa1) [21]. The dynamin-like guanosine triphosphatase (GTPase), mitofusion 1 (Mfn1), and mitofusion 2 (Mfn2) are involved in mitochondrial fusion [22]. Mitochondrial fission is controlled by dynamin-related protein 1 (Drp1) $[23,24]$, which is principally scattered in the cytoplasm and passes to the mitochondrial surface [25], inducing fission when overaccumulated around mitochondria. Meanwhile, mitochondrial fission protein 1 (Fis1) promotes the recruitment of Drp1 [26]. In addition, mitochondrial adaptors, such as mitochondrial fission factor (Mff) [27], mitochondrial dynamics proteins 49/51 (MID49/51) [28], and mitochondrial elongation factor 1 (Mef 1) [29], are involved in such process. Additionally, accumulating pieces of evidence indicate that mitochondrial fragmentation resulted from imbalanced fusion and fission and was associated with mitochondrial functional impairment and even cell destruction $[30,31]$. However, whether and how $\mathrm{TiO}_{2} \mathrm{NPs}$ affect mitochondrial structure and function still need to be elucidated to better depict the cytotoxicity of $\mathrm{TiO}_{2} \mathrm{NPs}$.

HT22 cells, derived from primary-cultured mouse hippocampal neurons [32], serve as a cell line of hippocampus neurons of the brain. In this study, we applied the stimulated emission depletion (STED) microscopy technique to study the structure of mitochondria in HT22 cells under $\mathrm{TiO}_{2}$ NPs insult, since it has the advantage of higher resolution than the conventional confocal microscopy $[33,34]$.

\section{Materials and Methods}

2.1. $\mathrm{TiO}_{2}$ NPs Preparation. $\mathrm{oTiO}_{2} \mathrm{NPs}$ from anatase(Cat. \#637254, Sigma-Aldrich, St. Louis, MO, USA) were dispersed in $10 \mathrm{~mL}$ of sterile double-distilled water in a centrifuge tube; then, the stock suspensions were ultrasonically treated in a bath sonicator $(40 \mathrm{kHz}, 60 \mathrm{~W})$ at room temperature for more than 30 minutes before being diluted with culture medium to the specified concentrations $(0.032 \mu \mathrm{g} / \mathrm{mL}, \quad 0.16 \mu \mathrm{g} / \mathrm{mL}, \quad 0.8 \mu \mathrm{g} / \mathrm{mL}, \quad 4 \mu \mathrm{g} / \mathrm{mL}, \quad$ and $20 \mu \mathrm{g} / \mathrm{mL}$ ). According to a previous study [35], we chose the moderate and even lower doses as suggested above. The $\mathrm{TiO}_{2}$ NPs suspensions used for the characterization below were dissolved in double-distilled water.

2.2. Characterization. For transmission electron microscopy (TEM) analysis, $\mathrm{TiO}_{2}$ NPs suspensions were prepared as above. $\mathrm{TiO}_{2}$ NPs suspensions $(0.8 \mu \mathrm{g} / \mathrm{mL}$ and $20 \mu \mathrm{g} / \mathrm{mL}$, dissolved in double-distilled water) were drop-coated on carbon-coated copper grids. The sample suspensions on the grids were dried out in air before measurement. The tests were performed at an accelerating voltage of $200 \mathrm{kV}$ using a JEOL-2010 TEM (Japan Electron Optics Laboratory, Tokyo, Japan).
$\mathrm{TiO}_{2}$ NPs suspensions were added to a disposable low volume cuvette $(50 \mu \mathrm{L})$. The average size distribution and zeta potential of $\mathrm{TiO}_{2}$ NPs were detected by dynamic light scattering (DLS) using a Zetasizer Nano ZS90 (Malvern Instruments, Malvern, Worcestershire, UK).

2.3. Cell Culture. HT22 cells were from AllCells (Shanghai Biological Technology Co. Ltd., Shanghai, China). We carried out some experiments in the $\mathrm{BE}(2) \mathrm{C}$ cell line, which is a human neuroblastoma cell line. The cells were planted in Dulbecco's minimum essential medium (DMEM), added with $10 \%(v / v)$ fetal bovine serum (FBS, qualified, Gibco, Australia origin) at $37^{\circ} \mathrm{C}$ in a $5 \%(v / v) \mathrm{CO}_{2}$ incubator. The cells of experimental groups were treated with corresponding concentrations of $\mathrm{TiO}_{2}$ NPs.

2.4. MitoTEMPO Incubation. MitoTEMPO (2-(2,2,6,6-tetramethylpiperidin-1-oxyl-4-ylamino)-2-oxoethyl)triphenylphosphonium chloride $(10 \mu \mathrm{M}$, Sigma-Aldrich) was preincubated in cells 1 hour before being stimulated with/without $20 \mu \mathrm{g} / \mathrm{mL}$ of $\mathrm{TiO}_{2} \mathrm{NPs}$ to eliminate the mitochondrial ROS. The experiments consist of four groups (control, $\mathrm{TiO}_{2}$ NPs, $\mathrm{TiO}_{2}$ NPs+mitoTEMPO, and mitoTEMPO).

2.5. Confocal Imaging. Cells were cultured with/without $\mathrm{TiO}_{2}$ NPs for $24 \mathrm{~h}$. The culture medium was wiped off, the cells were washed 3 times with phosphate-buffered saline (PBS),

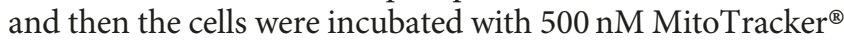
Red CMXRos (Invitrogen, Pleasanton, CA, USA) at $37^{\circ} \mathrm{C}$ for $30 \mathrm{~min}$ in a $5 \%(v / v) \mathrm{CO}_{2}$ incubator. The solution was removed, the cells were washed with PBS 3 times, and then the mitochondrial morphology was analyzed with a confocal microscope (ZEISS LSM710, Carl Zeiss, Oberkochen, Germany). NIH ImageJ software (Scion Corporation, Frederick, MD, USA) was used to quantify and measure the fluorescent signals of mitochondrial length and density [36].

2.6. STED Imaging. For submitochondrial structure imaging, STED super-resolution light microscopy was applied. Cells were prepared in the same way for confocal imaging. The cells were incubated with $500 \mathrm{nM}$ MitoTracker ${ }^{\circledR}$ Red CMXRos (Invitrogen) at $37^{\circ} \mathrm{C}$ for $30 \mathrm{~min}$ in the $5 \%(v / v)$ $\mathrm{CO}_{2}$ incubator. The solution was removed, and the remaining cells were washed with PBS 3 times. A Leica TCS SP8 STED 3x microscope (Leica Microsystems) equipped with a white light pulse laser (WLL2), STED laser $(775 \mathrm{~nm})$, oil immersion 100x/NA 1.4 objective lens (HC PL APO CS2, Leica), and TCS SP8 time-gated system was used. Images were acquired in both confocal mode and STED mode with $1024 \times 1024$ resolution at the same time. The obtained confocal and STED images were further deconvolved with the Huygens Professional software (Scientific Volume Imaging). NIH ImageJ software (Scion Corporation, Frederick, MD, USA) was used to measure the intensity of mitochondrial fluorescent signals. The images were rendered with pseudocolor to distinguish from images rendered only by confocal microscopy.

2.7. Western Blot Analysis. To compare the mitochondrial and cytoplasmic proteins, the Mitochondria Isolation Kit 
for Cultured Cells (Thermo Fisher Scientific, Waltham, MA) was used to obtain mitochondrial and cytoplasmic proteins. The concentrations of the proteins were estimated by the BCA assay (P0010, Beyotime, Shanghai, China). Then, samples were diluted to the same concentration and boiled in water for $10 \mathrm{~min}$ before they were stored at $-20^{\circ} \mathrm{C}$. Sample proteins were added to $12 \%$ sodium dodecyl sulfate polyacrylamide gel electrophoresis (SDS-PAGE) gels at $120 \mathrm{~V}$. The separated proteins on the gel were transferred to $0.45 \mu \mathrm{m}$ polyvinylidene difluoride (PVDF) membranes (Millipore, Billerica, MA, USA) at $300 \mathrm{~mA}$ for $45 \mathrm{~min}$. Then, the membranes were incubated with $10 \%(\mathrm{~m} / \mathrm{v})$ fat-free milk at room temperature for $1 \mathrm{~h}$. The blots were initially incubated overnight at $4{ }^{\circ} \mathrm{C}$ with the following primary antibodies: anti-extracellular-regulated protein kinases $1 / 2$ (erk1/2) (\#9102s, Cell Signaling Technology, Danvers, MA, USA), anti-phospho-erk1/2 (\#4376s, Cell Signaling Technology), anti-Drp1 (611113, BD Biosciences, San Diego, CA, USA), anti-opa1 (612606, BD Biosciences), anti-COXIV (ab14744, Abcam, Cambridge, MA, USA), anti-glyceraldehyde-3phosphate dehydrogenase (GAPDH) (AB2302, Millipore), anti-Cyt C (sc-7159, Santa Cruz Biotechnology Inc., Dallas, TX, USA), anti-caspase 9 (AC062, Beyotime), anti-Bcl-2 (AB112, Beyotime), and anti-Bax (AB026, Beyotime). The following are the secondary antibodies: antichicken immnunoglobins of yolk (IgY), HRP conjugate (G135, Promega Corp., Madison, WI, USA), anti-mouse immunoglobulin G (IgG), HRP conjugate (W4021, Promega Corp.), and anti-rabbit IgG, HRP conjugate (W4011, Promega Corp.). NIH ImageJ analysis software (Scion Corporation, Frederick, MD, USA) was used to analyze the density.

2.8. Measurement of Oxidative Stress Markers. To measure the oxidative activity, the levels of ROS, malondialdehyde (MDA), and glutathione (GSH) were evaluated. The experiments were carried out according to protocols provided by each assay kit (Beyotime). Each sample was measured using an automated microplate spectrophotometer (CLARIOstar, BMG LABTECH, Offenburg, Germany). The values of ROS, MDA, and GSH obtained for untreated cells were considered $100 \%$.

\subsection{Measurement of Mitochondrial Membrane Potential} $(M M P)$. MMP was measured using rhodamine 123 (Rh-123) staining. Rh-123 (10 $\mu \mathrm{M})$ was treated to HT22 cells and incubated at $37^{\circ} \mathrm{C}$ for $30 \mathrm{~min}$. Rh-123 can enter the mitochondrial matrix and the fluorescence strength reflects mitochondrial transmembrane potential. When the excitation wavelength was $480 \mathrm{~nm}$, the fluorescence was analyzed with a fluorescence microplate reader (CLARIOstar, BMG LABTECH, Offenburg, Germany). The values of MMP obtained for untreated cells were considered $100 \%$.

2.10. Measurement of Cellular Concentration of ATP. The release of ATP was assessed using an ATP assay kit (S0026, Beyotime). First, excessive medium was removed. Then, HT22 cells were dissociated with lysis buffer at $4^{\circ} \mathrm{C}$. The lysates were centrifuged at $12,000 \mathrm{~g}$ for 5 minutes, and then the supernatants were collected. ATP concentration was measured using a microplate reader (CLARIOstar, BMG LABTECH, Offenburg, Germany). The values of ATP obtained for untreated cells were considered $100 \%$.

2.11. Hoechst 33342/Propidium Iodide (PI) Analysis. $\mathrm{TiO}_{2}$ NPs-induced cell death was detected by a Hoechst 33342/PI detection kit (Beyotime). HT22 cells were added with corresponding concentrations of $\mathrm{TiO}_{2} \mathrm{NPs}$ for 24 or $48 \mathrm{~h}$. Firstly, $10 \mu \mathrm{L}$ of Hoechst 33342 was put into the wells with a total medium of $1 \mathrm{~mL}(1: 100)$ at $37^{\circ} \mathrm{C}$ for $10 \mathrm{~min}$; then, $5 \mu \mathrm{L}$ of PI diluted with a total of $1 \mathrm{~mL}$ of medium $(1: 200)$ was put into the wells for another $10 \mathrm{~min}$ at room temperature. Fluorescence was measured at both excitation wavelengths of $352 \mathrm{~nm}$ and $488 \mathrm{~nm}$ using a microscope (Olympus IX81, Tokyo, Japan). Image-Pro Plus 6.0 software (Media Cybernetics Inc., MD, USA) was used to count the cell numbers.

2.12. Annexin V-Fluorescein Isothiocyanate and Propidium Iodide (Annexin V-FITC/PI) Staining. To further assess the effect of $\mathrm{TiO}_{2}$ NPs on cell apoptosis, an Annexin V-FITC/PI assay was conducted. Cultured HT22 cells were collected 24 or $48 \mathrm{~h}$ after $\mathrm{TiO}_{2}$ NPs exposure. Cells were then resuspended in binding buffer after washing with PBS. The cell suspensions were then treated with both Annexin V-FITC/PI at room temperature for $20 \mathrm{~min}$ in the dark. Cell suspensions were analyzed by a FACS Vantage flow cytometer (Becton Dickinson, CA, USA). The results were then analyzed using FlowJo software (FlowJo, OR, USA). Each quadrant indicated the different status of the cells. Q4 indicated surviving cells, Q3 indicated cells in early apoptosis, Q2 indicated cells in late-stage apoptosis, and Q1 indicated dead cells.

2.13. Mitochondrial Superoxide Assay. To monitor mitochondrial superoxide after $\mathrm{TiO}_{2}$ NPs treatment, MitoSOX Red (5 $\mu \mathrm{M}$, Invitrogen) was loaded into the cells that were treated with/without $\mathrm{TiO}_{2} \mathrm{NPs}$ for $24 \mathrm{~h}$. After removing the culture medium and washing twice, the solution of MitoSOX Red diluted in $\mathrm{HBSS} / \mathrm{Ca} / \mathrm{Mg}$ was added into HT22 cells at $37^{\circ} \mathrm{C}$ for $10 \mathrm{~min}$ in the dark. The cells were washed twice with prewarmed $\mathrm{HBSS} / \mathrm{Ca} / \mathrm{Mg}$ to remove the excessive probes. To avoid saturation by excessive oxidation, all MitoSOX experiments were completed within $30 \mathrm{~min}$ of loading. Each sample was measured using an automated microplate spectrophotometer (CLARIOstar, BMG LABTECH, Offenburg, Germany). The excited wavelength of MitoSOX Red is $510 \mathrm{~nm}$, and the emitted wavelength is $580 \mathrm{~nm}$. The values of MitoSOX Red obtained for untreated cells were considered $100 \%$. The images of MitoSOX Red and Hoechst33342 costaining were collected using a microscope (Olympus IX81, Tokyo, Japan). The intensity was subsequently analyzed by using NIH ImageJ software.

2.14. Statistical Analysis. All experiments were conducted at least three times. The statistical results are expressed as the mean \pm standard error (SE). The data were analyzed with one-way analysis of variance followed by Bonferroni's post hoc comparisons test using Origin Pro 8.0 (OriginLab Corporation, MA, USA). The differences were considered 


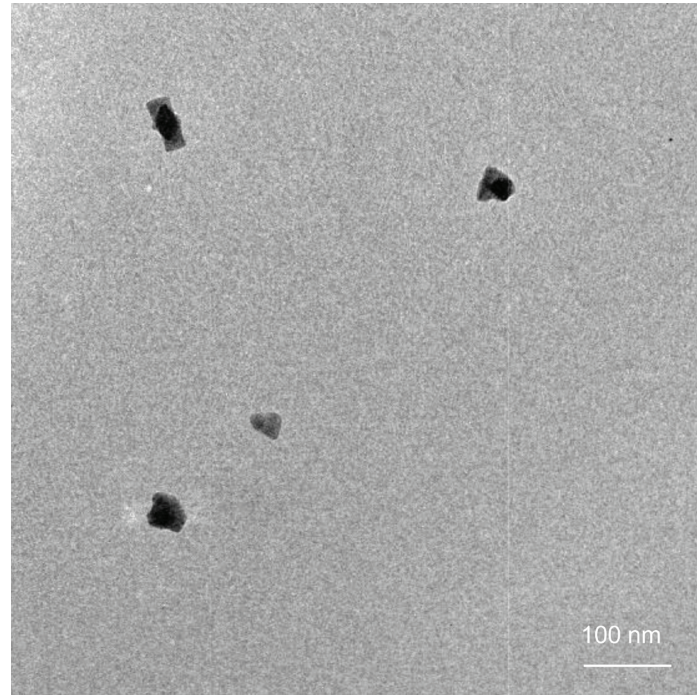

(a)

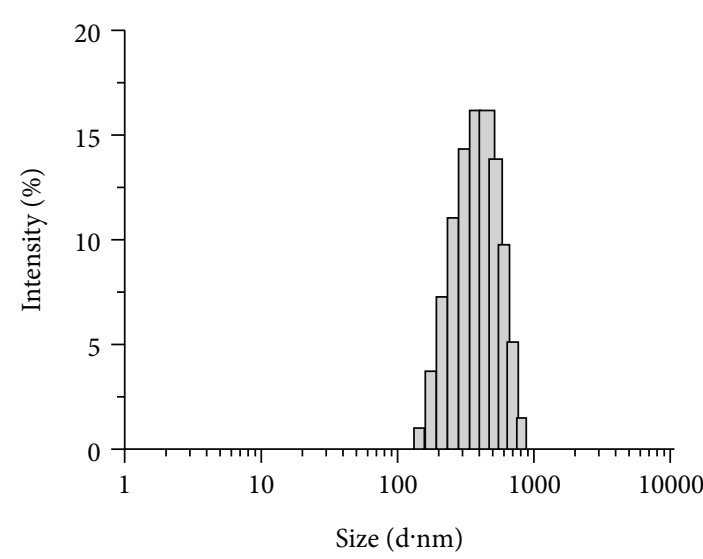

(c)

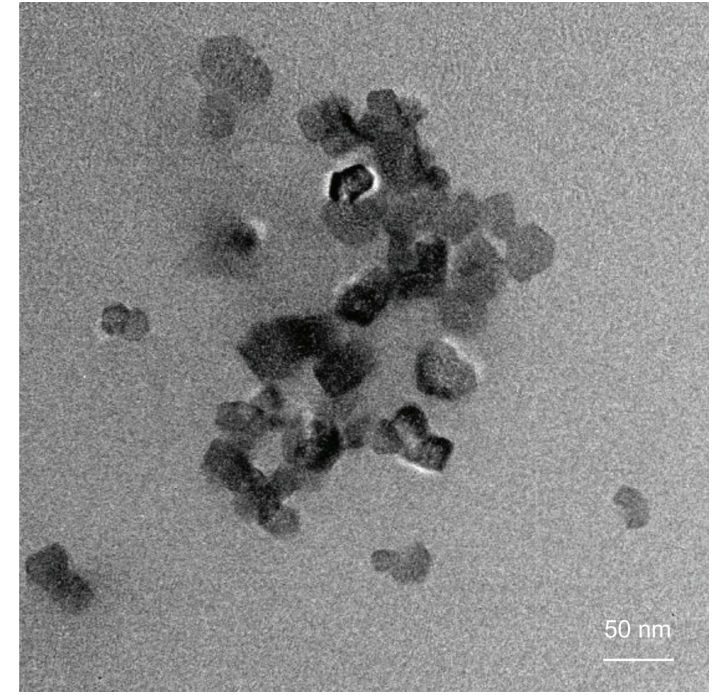

(b)

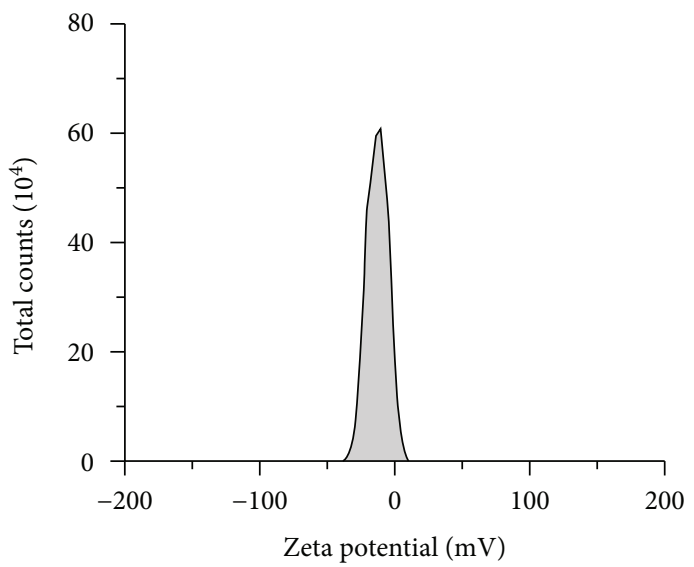

(d)

FIgure 1: The characterization of titanium dioxide nanoparticles $\left(\mathrm{TiO}_{2} \mathrm{NPs}\right)$. TEM photomicrographs of $\mathrm{TiO}_{2} \mathrm{NPs}_{\text {at }}$ (a) low concentration $(0.8 \mu \mathrm{g} / \mathrm{mL})$ and (b) high concentration $(20 \mu \mathrm{g} / \mathrm{mL})$. (c) The size of $\mathrm{TiO}_{2}$ NPs measured in water by electrophoresis light scattering. (d) The zeta potential of $\mathrm{TiO}_{2} \mathrm{NPs}$ in water by dynamic light scattering.

statistically significant when $p<0.05$. The graphs were drawn using Origin Pro 8.0.

\section{Results}

3.1. Characterization of $\mathrm{TiO}_{2}$ NPs. The particle size of the $\mathrm{TiO}_{2} \mathrm{NPs}$ was observed by TEM after dissolution in water. $\mathrm{TiO}_{2}$ NPs were dispersed at a low concentration $(0.8 \mu \mathrm{g} / \mathrm{mL})$ and agglomerated at a high concentration $(20 \mu \mathrm{g} / \mathrm{mL})$ in the water (Figures 1(a) and 1(b)). According to DLS results, the $Z$-average of $\mathrm{TiO}_{2} \mathrm{NPs}$ in the water was $270.73 \pm 5.19 \mathrm{~nm}$ (Figure 1(c)), which meant that the hydrodynamic diameter of $\mathrm{TiO}_{2} \mathrm{NPs}$ was much larger than the size revealed by TEM. The size distribution (PDI) was $0.35 \pm 0.03$. The surface zeta potential of $\mathrm{TiO}_{2} \mathrm{NPs}(\mathrm{pH} 7.86)$ was $-18.08 \pm$ $1.32 \mathrm{mV}$ (Figure $1(\mathrm{~d})$ ), showing a negative surface charge in the water. The results were consistent with the findings in the previous study [37].
3.2. $\mathrm{TiO}_{2} \mathrm{NPs}$-Induced Mitochondrial Fragmentation. The mitochondrial morphology would change from normal to fragmented in pathological conditions. As shown in Figures 2(a) and 2(b), control cells showed normal mitochondria, while cells under $\mathrm{TiO}_{2}$ NPs treatment showed fragmented mitochondrial structures, suggesting that the mitochondria were promoted to the fission state by $\mathrm{TiO}_{2}$ NPs exposure. Mitochondrial density in whole cells was reduced in the $\mathrm{TiO}_{2} \mathrm{NPs}$-treated groups compared with that in control cells (Figure 2(c)). Moreover, mitochondrial length was significantly shorter in the $\mathrm{TiO}_{2} \mathrm{NPs}$-treated cell than that in control cells (Figure 2(d)). We found that mitochondrial fragmentation in the $\mathrm{TiO}_{2}$ NPs-treated cells $(20 \mu \mathrm{g} / \mathrm{mL})$ could largely be prevented by mitoTEMPO incubation (Supplementary Figure 1). The similar results were shown in BE2C cell (Supplementary Figure 2).

3.3. Submitochondrial Structures in Mitochondria. Compared with the length of the mitochondrial tubules shown in 
$\mathrm{TiO}_{2} \mathrm{NPs}(\mu \mathrm{g} / \mathrm{ml})$
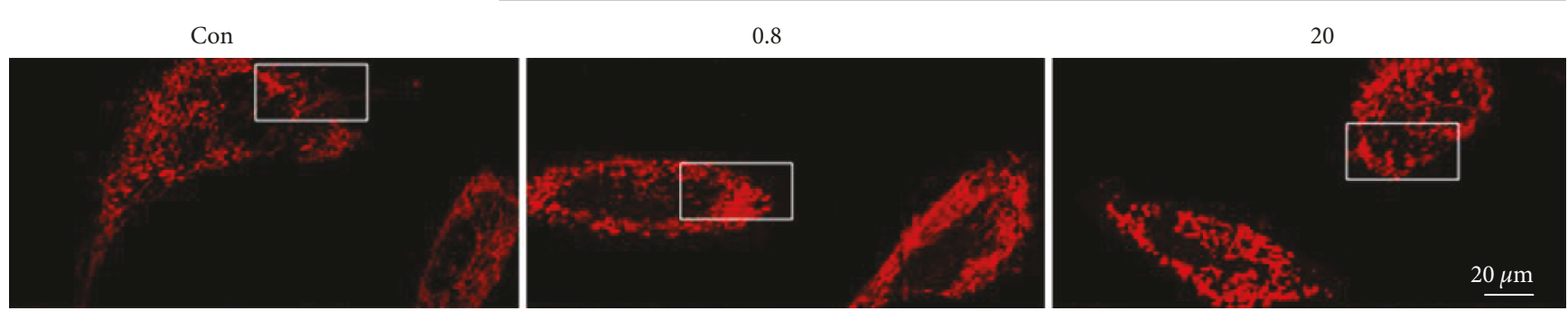

(a)

$\mathrm{TiO}_{2} \mathrm{NPs}(\mu \mathrm{g} / \mathrm{ml})$

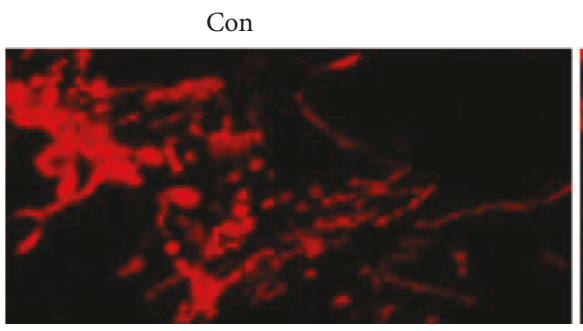

0.8
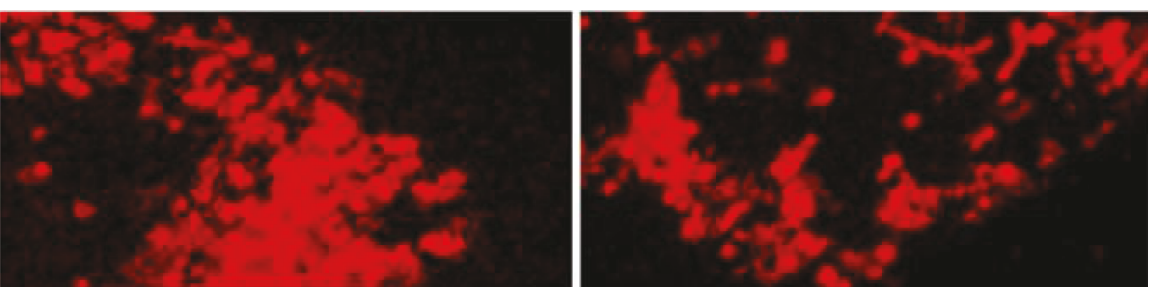

(b)
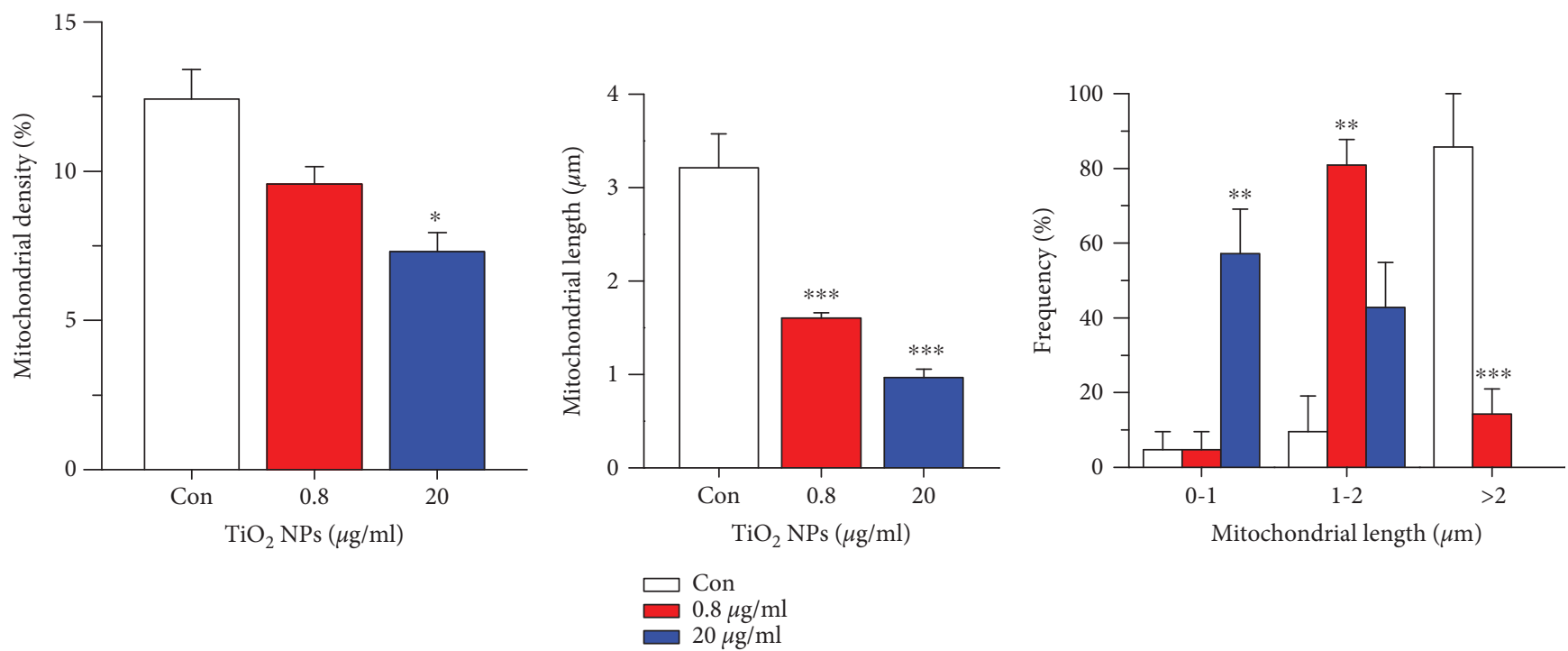

(c)

(d)

Figure 2: $\mathrm{TiO}_{2}$ NPs exposure caused mitochondrial fragmentation in HT22 cells. (a) Representative confocal images. (b) Enlarged images of the square frames shown in (a). Scale bars: $20 \mu \mathrm{m}$ in (a). (c) Quantitative analysis of mitochondrial density in entire cells. (d) The average length of the mitochondria in entire cells and quantification of the size of mitochondria according to the grouped differently sized bins. $n=7$ cells/group. $\left({ }^{*} p<0.05,{ }^{* *} p<0.01\right.$, and $\left.{ }^{* * *} p<0.001\right)$.

confocal microscopy, STED images further obtained the nanoscale submitochondrial structures of the mitochondria. Diffraction-limited confocal microscopy demonstrated that mitochondrial tubules were largely homogenously stained, and the mitochondrial tubules were shorter in the $\mathrm{TiO}_{2}$ NPs-treated cells than in control cells (Figure 3(a)). Besides, the STED images showed the complex and lamellar submitochondrial structure in the control group and diffused and distributed submitochondrial structure in the $\mathrm{TiO}_{2}$ NPs-treated groups, with short flaked and punctate spots (Figures 3(b) and 3(c)). Then, the fluorescence intensity distributions of submitochondrial structures along long axis of mitochondria show that the peaks of intensity were focused in the control group, but there were many peaks in the $\mathrm{TiO}_{2} \mathrm{NPs}$-treated groups (Figures 3(d) $-3(\mathrm{f})$ ).

3.4. $\mathrm{TiO}_{2} \quad \mathrm{NPs}$ Induced Imbalanced Expression of Mitochondrial Fission/Fusion Protein. Mitochondria and cytoplasmic proteins were independently isolated for Western blot analysis. As shown in Figure 4(a), Drp1 


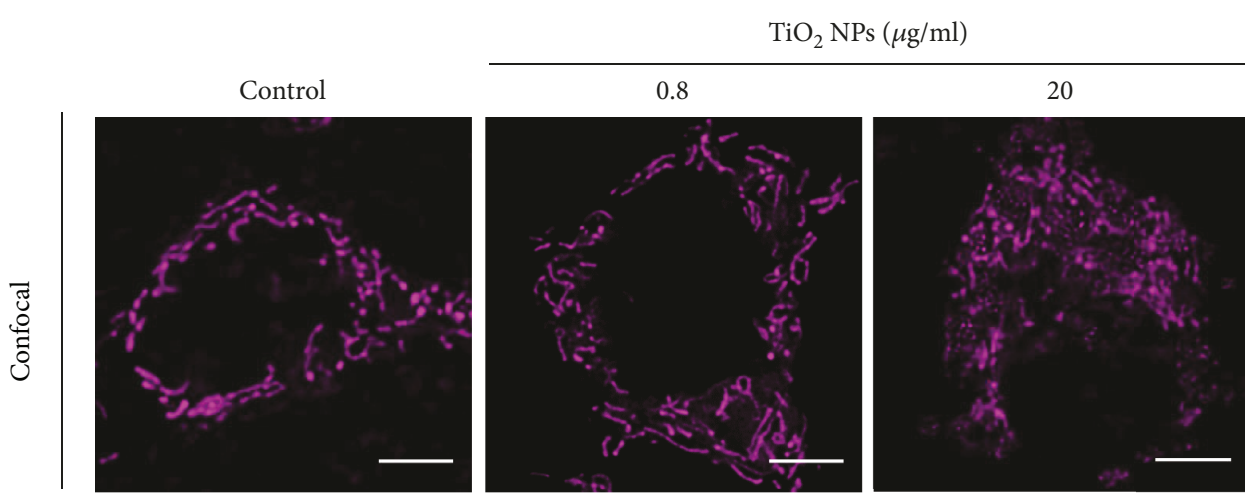

(a)
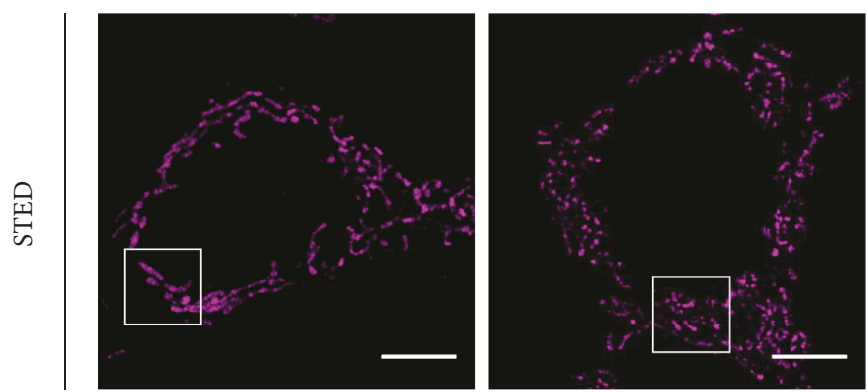

(b)

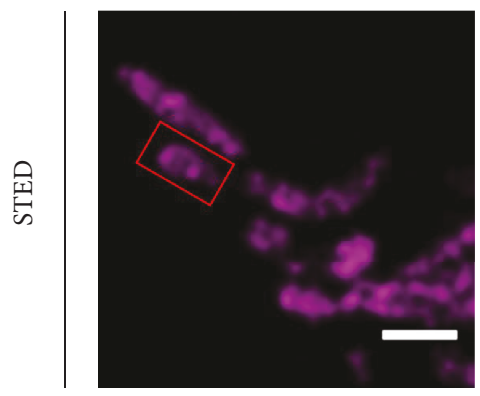

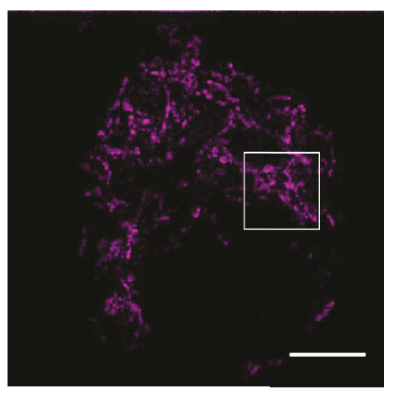

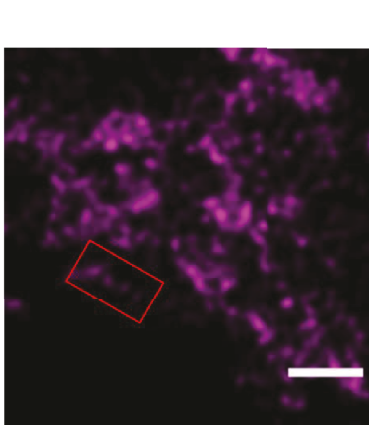

(c)

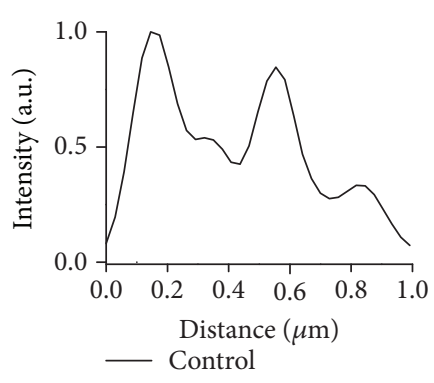

(d)

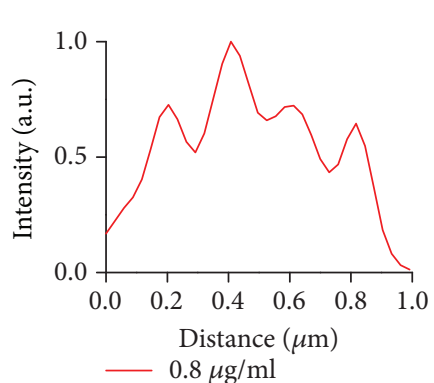

(e)

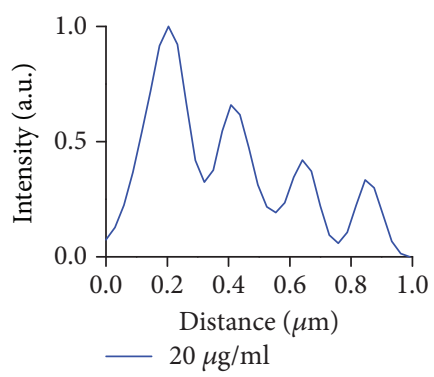

(f)

FIGURE 3: STED super-resolution microscopy revealed submitochondrial structures. (a) Confocal microscopy of mitochondria in control, $0.8 \mu \mathrm{g} / \mathrm{mL}$, and $20 \mu \mathrm{g} / \mathrm{mL}$ groups. (b) STED super-resolution microscopy revealed submitochondrial structures of the same region using confocal microscopy. (c) Enlarged views of the white boxes in (b). (d-f) Averaged intensity distribution along the mitochondrial tubule sections in the corresponding red boxes in (c). Scale bars: $5 \mu \mathrm{m}$ in (a) and (b); $1 \mu \mathrm{m}$ in (c).

translocated to the mitochondria at a high concentration of $\mathrm{TiO}_{2}$ NPs exposure, while Opal in mitochondria was decreased (Figure 4(b), $p<0.05$ ). For cytoplasmic proteins, there were no significant differences in Drp1 or Opa1 in the experimental groups (Figure 4(b), $p>0.05$ ). This demonstrated that $\mathrm{TiO}_{2}$ NPs treatment in HT22 cells led to the accumulation of Drp1 to mitochondria while Opal was decreased, which may cause excessive mitochondrial fission. These results are consistent with the morphological changes of mitochondria. The imbalanced expression of dynamin-related protein 1 (Drp1) and optic atrophy 1 (Opa1) could largely be prevented by mitoTEMPO incubation (Supplementary Figure 3).

3.5. ROS Generation and Oxidative Stress Levels. The induction of intracellular oxidation was measured using a $2^{\prime}, 7^{\prime}$-dichlorodihydrofluorescein diacetate (DCF-DA) probe to report ROS generation. Cells treated with $\mathrm{TiO}_{2} \mathrm{NPs}$ exhibited increased fluorescence intensity when compared to the control (Figure 5(a), $p<0.05$ ). Some other parameters connected with oxidative stress, such as the levels of MDA or GSH, were tested as well. MDA serves as a marker of lipid peroxidation. Its level determines the degree of damage to the membrane system. The results showed that MDA levels were significantly higher in the $\mathrm{TiO}_{2}$ NPs-treated group than in the control group (Figure 5(b), $p<0.05$ ). GSH concentration directly reflects tissue antioxidant levels. There was a significant decrease in the level of GSH in the $\mathrm{TiO}_{2}$ NPs-treated group compared to that in the control group (Figure 5(c), $p<0.05$ ). These results clearly indicated that the oxidative stress level was elevated in the $\mathrm{TiO}_{2} \mathrm{NPs}$-treated cells. Furthermore, we examined oxidative stress (e.g., ROS, MDA, and GSH), which indicated that the oxidative stress under $\mathrm{TiO}_{2} \mathrm{NPs}$ exposure can be reversed by mitoTEMPO incubation (Supplementary Figure 4 A-C). 


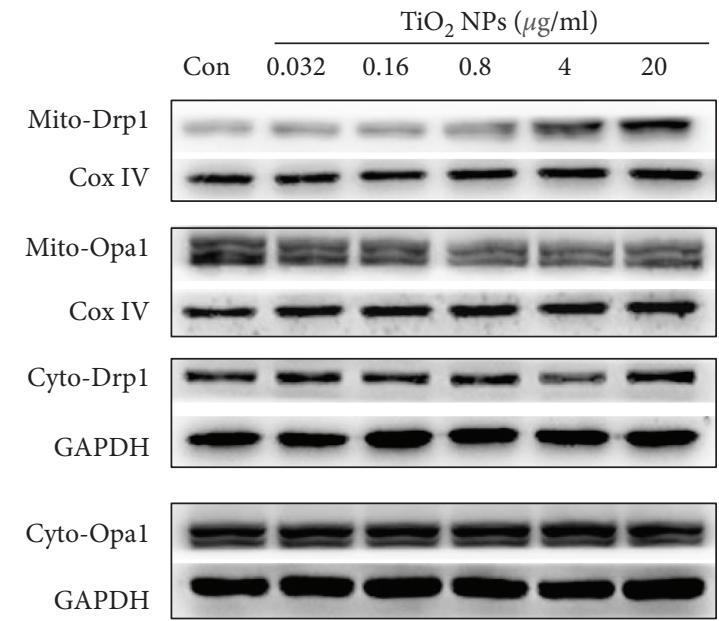

(a)
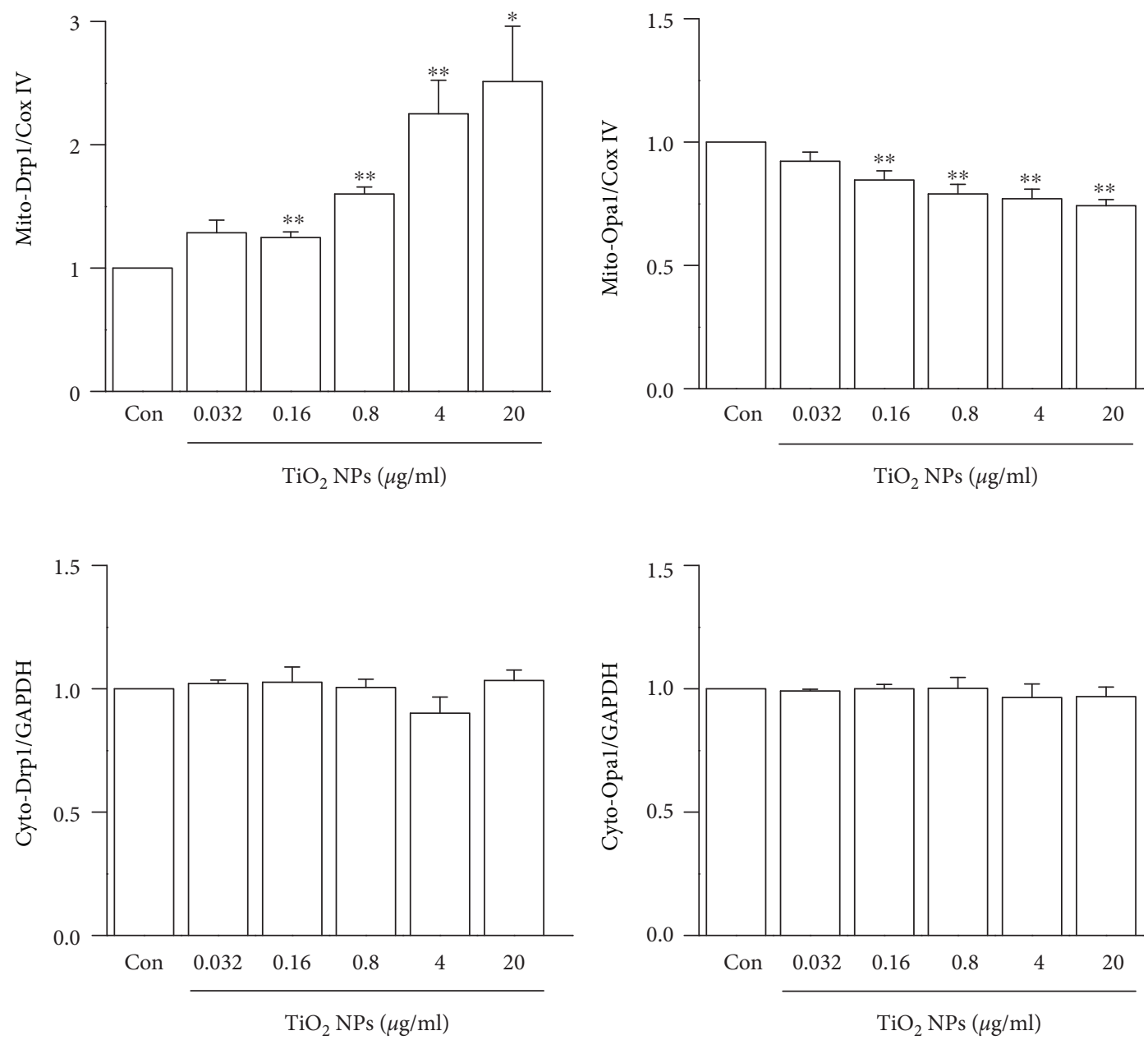

(b)

FIGURE 4: $\mathrm{TiO}_{2}$ NPs exposure caused imbalanced mitochondrial fission/fusion protein levels. (a) Representative Western blot bands of Drp1

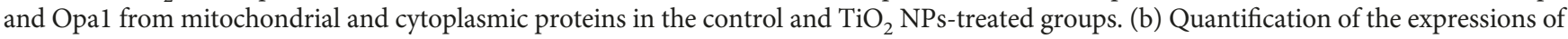
Drp1 and Opa1 from mitochondrial and cytoplasmic proteins. $\left({ }^{*} p<0.05\right.$ and $\left.{ }^{* *} p<0.01\right)$. Drp1: dynamin-related protein 1; Opa1: optic atrophy 1; COXIV: cytochrome c oxidase IV; GAPDH: glyceraldehyde-3-phosphate dehydrogenase. 


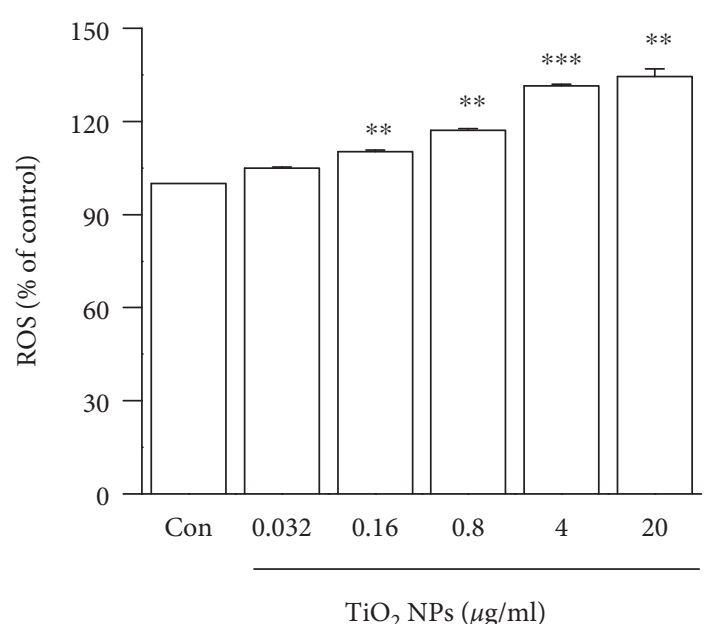

(a)

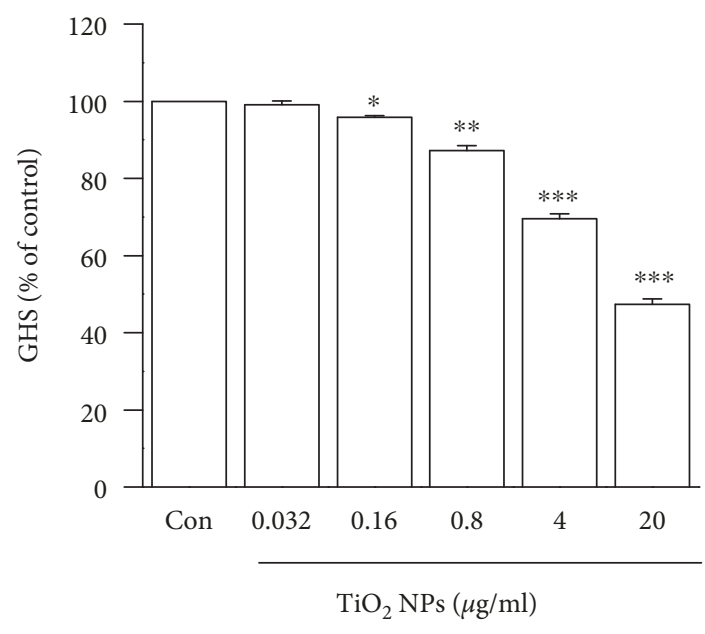

(c)

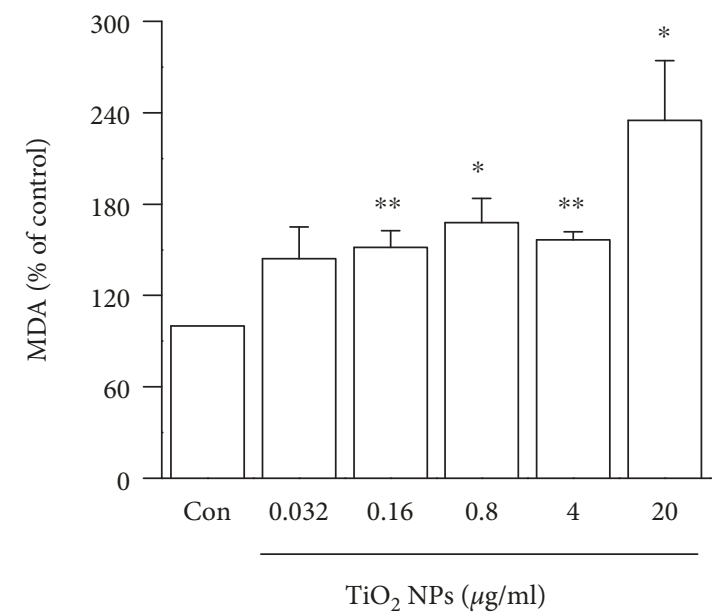

(b)

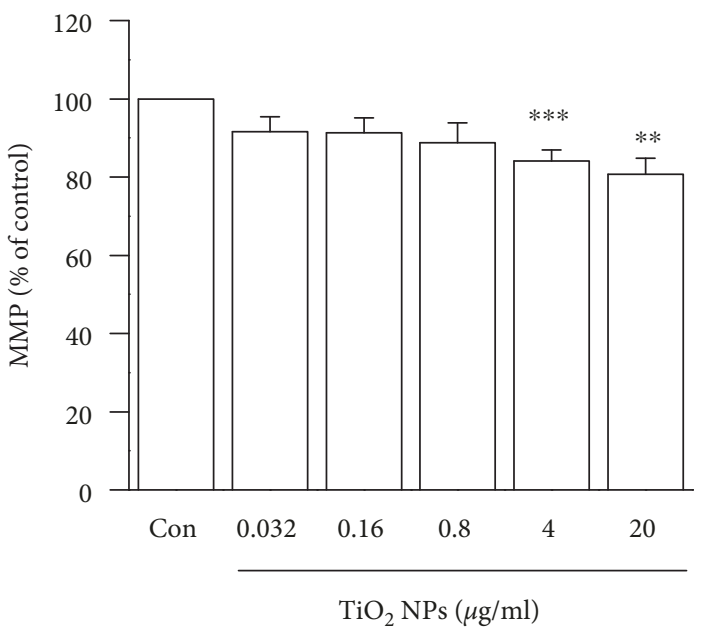

(d)

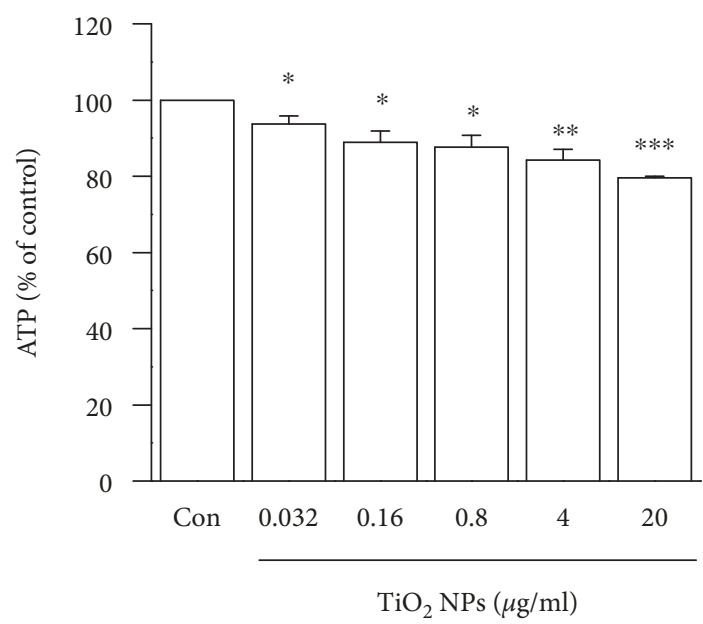

(e)

Figure 5: Effect of $\mathrm{TiO}_{2}$ NPs exposure on oxidative stress, mitochondrial membrane potential, and the production of ATP in HT22 cells. (a) ROS levels, (b) MDA levels, (c) GSH levels, (d) MMP, and (e) ATP production. $\left({ }^{*} p<0.05,{ }^{* *} p<0.01\right.$, and ${ }^{* * *} p<0.001$.) ROS: reactive oxygen species; MDA: malondialdehyde; GSH: reduced glutathione hormone; MMP: mitochondrial membrane potential; ATP: adenosine triphosphate. 

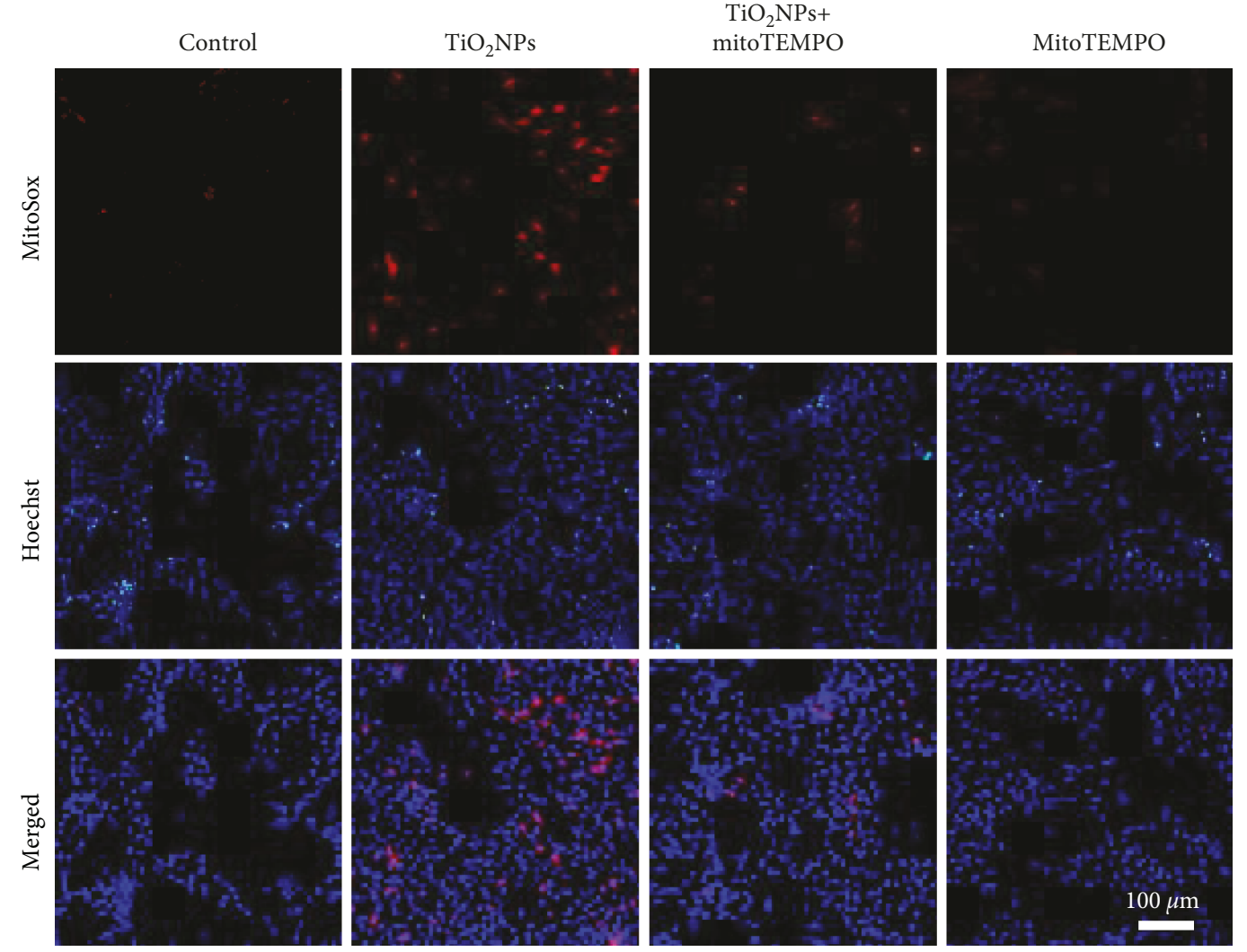

(a)

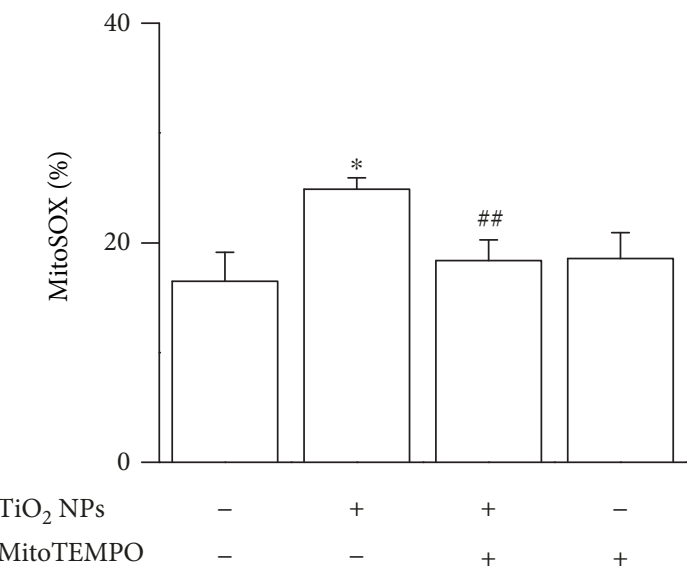

(b)

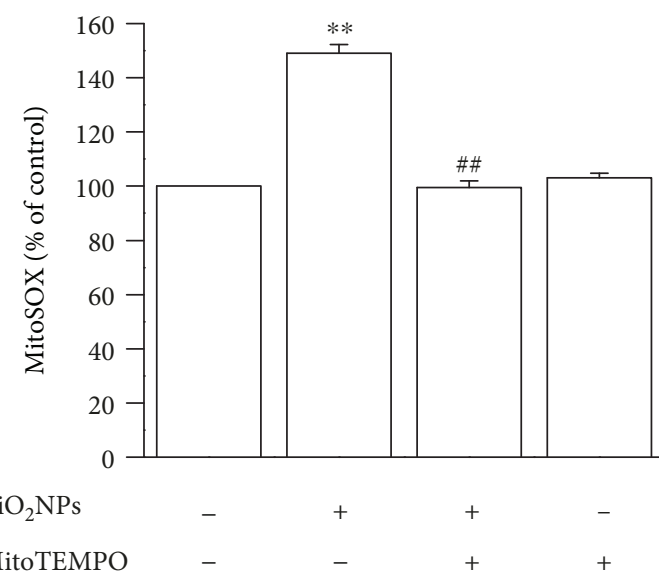

(c)

Figure 6: MitoTEMPO suppresses $\mathrm{TiO}_{2}$ NPs-induced mitochondrial superoxide production in HT22 cells. (a) Representative images of MitoSOX Red (red) and Hoechst 33342 (blue) staining were revealed using a fluorescence microscope. (b) The statistics of the fluorescence intensity were revealed using a fluorescence microscope. (c) MitoSOX Red intensity was revealed using an automated microplate spectrophotometer $\left({ }^{*} p<0.05\right.$ vs. control group, ${ }^{* *} p<0.01$ vs. control group, and ${ }^{\# \#} p<0.01$ vs. $\mathrm{TiO}_{2} \mathrm{NPs}$ group).

Considering that mitochondria are vital ROS formation organelles, we further tested mitochondrial ROS generation in HT22 cells. The MitoSOX Red probe was used to detect the mitochondrial superoxide levels. The intensity of the MitoSOX Red fluorescence is proportionate to the abundance of the superoxide. To determine whether the application of mitoTEMPO attenuates $\mathrm{TiO}_{2}$ NPs-mediated mitochondrial ROS overproduction, HT22 cells were exposed with/without $\mathrm{TiO}_{2}$ NPs in the absence or presence of mitoTEMPO. Cells were pretreated with mitoTEMPO for $1 \mathrm{~h}$ before the addition of $\mathrm{TiO}_{2}$ NPs. A significantly increased MitoSOX Red intensity was detected in the $\mathrm{TiO}_{2}$ NPs-treated group in the absence of mitoTEMPO, while the $\mathrm{TiO}_{2}$ NPs-induced elevation of the mitochondrial superoxide was markedly attenuated by mitoTEMPO (Figure 6). The application of mitoTEMPO itself did not alter mitochondrial superoxide production (Figure 6). Similar results were shown in the BE2C cell (Supplementary Figure 5). 


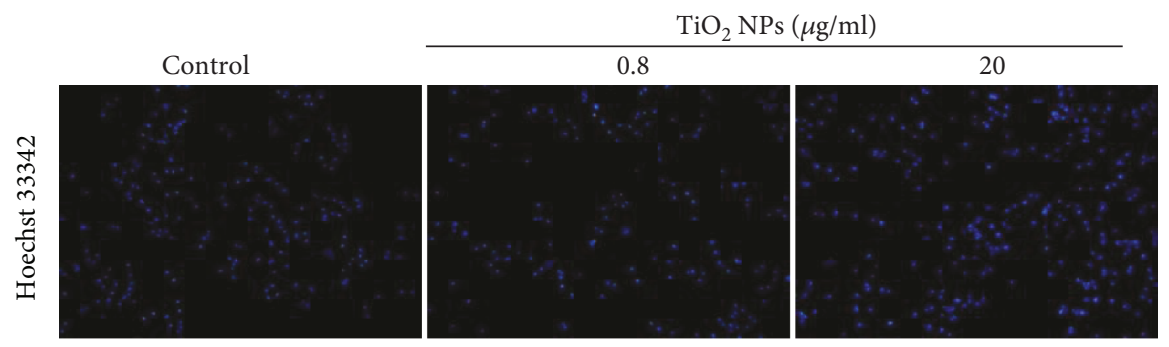

(a)

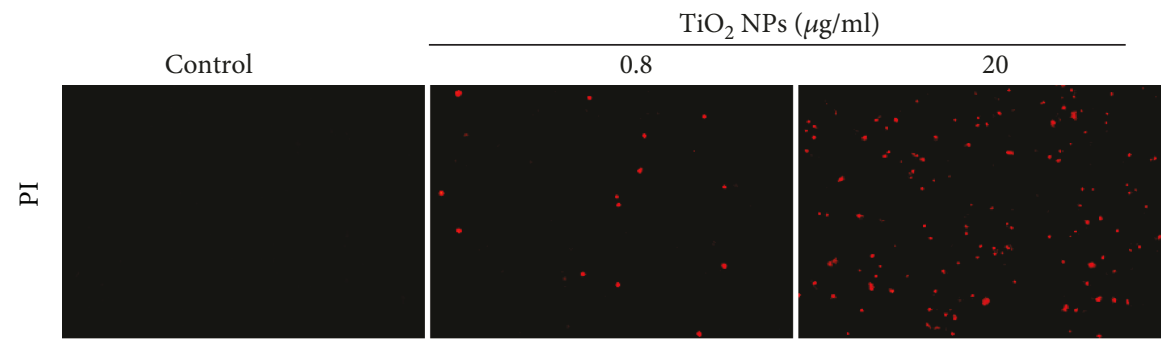

(b)

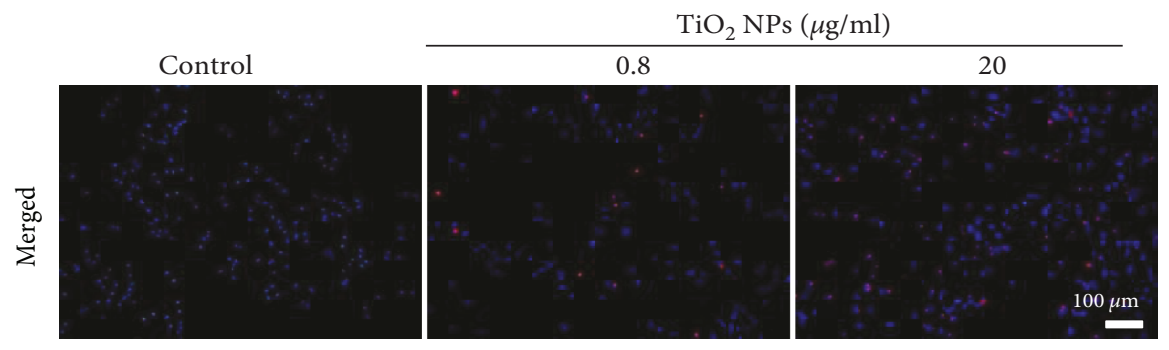

(c)
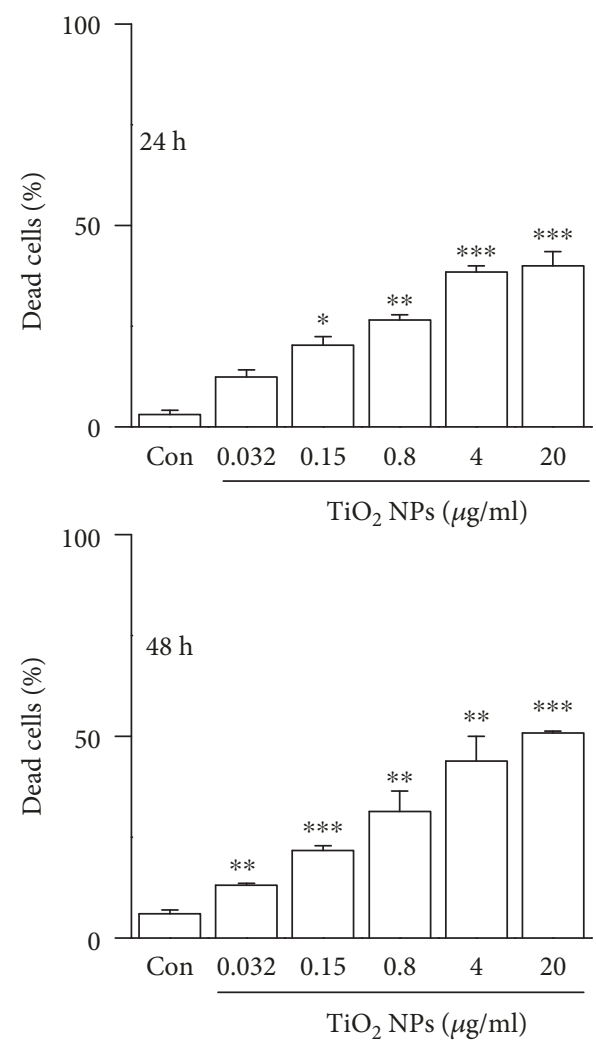

(d)

FIgURE 7: Continued. 


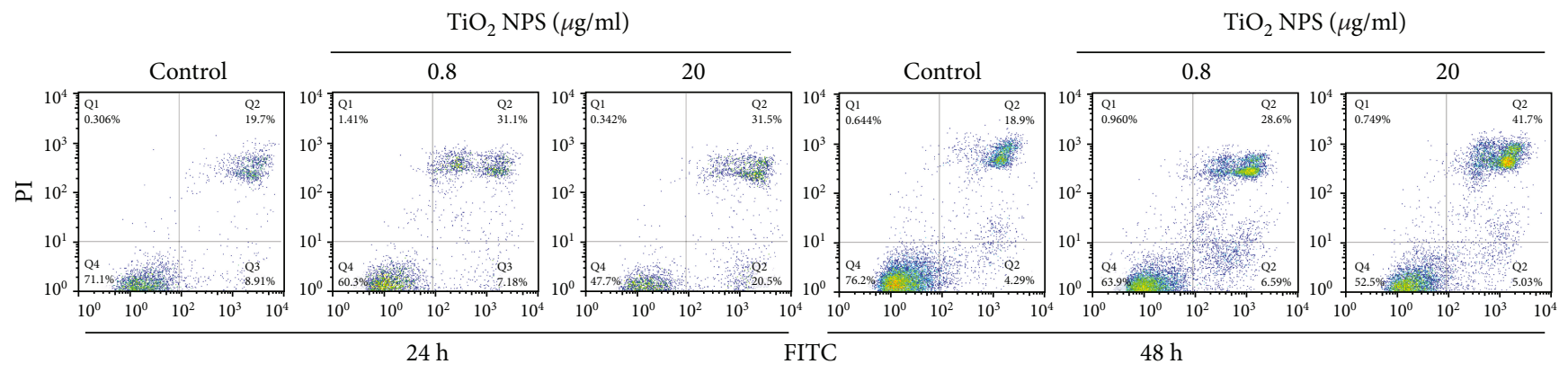

(e)

FIgure 7: Cytotoxicity induced by $\mathrm{TiO}_{2}$ NPs treatment. (a-d) Cell death caused by $\mathrm{TiO}_{2}$ NPs treatment in $\mathrm{HT} 22$ cells estimated by Hoechst $33342 / \mathrm{PI}$ staining. Typical fluorescence microscopy images of the control group and the groups treated with various concentrations of $\mathrm{TiO}_{2}$ NPs: (a) Hoechst 33342 (blue); (b) PI (red); (c) merged. (d) The proportion of dead cells after being treated for 24 and $48 \mathrm{~h}\left({ }^{*} p<0.05,{ }^{* *} p\right.$ $<0.01$, and $\left.{ }^{* * *} p<0.001\right)$. (e) Apoptosis and necrosis caused by $\mathrm{TiO}_{2} \mathrm{NPs}$ treatment in $\mathrm{HT} 22$ cells. Representative flow cytometry data of $\mathrm{TiO}_{2}$ NPs-treated HT22 cells showing the ratio of late apoptotic cells and early apoptotic cells in Q2 and Q3 for $24 \mathrm{~h}$ and $48 \mathrm{~h}$. FITC: fluorescein isothiocyanate; PI: propidium iodide.

3.6. Loss of Mitochondrial Membrane Potential and ATP. It is well known that ROS aggregation damages mitochondrial function. Mitochondrial function was further explored under $\mathrm{TiO}_{2}$ NPs insult. The loss of MMP was assessed using a $5,5^{\prime}, 6,6^{\prime}$-tetrachloro-1,1 $1^{\prime}, 3,3^{\prime}$-tetraethylimidacarbocyanine iodide (JC-1) assay kit, which showed that at a high concentration $(20 \mu \mathrm{g} / \mathrm{mL})$ of $\mathrm{TiO}_{2} \mathrm{NPs}, \mathrm{MMP}$ was significantly reduced in the HT22 cells (Figure 5(d), $p<0.05)$. The production of ATP was estimated with an ATP assay kit. It was found that $\mathrm{TiO}_{2}$ NPs treatment significantly decreased ATP production at high concentrations $(20 \mu \mathrm{g} / \mathrm{mL})$ (Figure 5(e), $p<0.05)$. Furthermore, we examined mitochondrial membrane potential and the generation of ATP, which showed that the damage of mitochondrial function under $\mathrm{TiO}_{2}$ NPs exposure can be reversed by mitoTEMPO incubation (Supplementary Figures 4D and 4E).

3.7. $\mathrm{TiO}_{2} \mathrm{NPs}$-Induced Cytotoxicity. Hoechst 33342/PI staining assays can distinguish dead cells. Hoechst 33342 can go across the cell membrane of normal cells and apoptotic cells showing blue fluorescence under ultraviolet light, while PI can go across the cell membrane of the necrotic cells to produce red fluorescence (Figures $7(\mathrm{a}), 7(\mathrm{~b})$, and 7(c)). With increasing concentrations of $\mathrm{TiO}_{2} \mathrm{NPs}$, the red fluorescence became stronger, indicating a higher proportion of dead cells at both 24 and $48 \mathrm{~h}$ (Figure $7(\mathrm{~d}), p<0.05$ ). Hoechst 33342 /propidium iodide (PI) analysis suggested that mitoTEMPO incubation can reverse the ratio of dead cells (Supplementary Figure 6). Similar results were shown in BE2C cells (Supplementary Figure 7).

To quantify the apoptosis of HT22 cells after $\mathrm{TiO}_{2}$ NPs treatment, Annexin V-FITC/PI double staining was conducted. The results showed an increase in apoptotic and necrotic cells when treated with $\mathrm{TiO}_{2} \mathrm{NPs}$ for $24 \mathrm{~h}$ (Figure $7(\mathrm{e})$ ). The trend was similar when treated for $48 \mathrm{~h}$ (Figure 7(e)).

3.8. $\mathrm{TiO}_{2} \mathrm{NPs}$-Induced Specific Expression of MitochondrialRelated Apoptosis Proteins. To explore the underlying mechanisms responsible for apoptosis induced by $\mathrm{TiO}_{2}$ NPs, the expression levels of Bcl-2, Bax, and caspase 9, as well as mitochondrial Cyt $\mathrm{C}$ were examined. As shown in Figure 8(a), there was a significant increase in the expression of caspase 9 and Bax, while a decrease of Bcl-2 and Cyt C in the $\mathrm{TiO}_{2}$ NPs-treated HT22 cells can be found (Figure 8(b), $p<0.05)$. The expression of $\mathrm{p}$-ERK was increased in the $\mathrm{TiO}_{2}$ NPs-treated cells (Figure 8(b), $p<0.05$ ). The significant changes of expressions of Bax, Bcl-2, Cyt C, caspase 9, and p-ERK caused by $\mathrm{TiO}_{2}$ NPs treatment could largely be reversed by mitoTEMPO incubation (Supplementary Figure 8).

\section{Discussion}

Mitochondria have been conventionally studied by biochemical, genetic, and electron microscopic approaches. To investigate mitochondrial dynamics under $\mathrm{TiO}_{2}$ NPs treatment, live-cell fluorescence microscopy was used as an indispensable tool to elucidate the mitochondrial dynamics. In this study, confocal microcopy was firstly used to observe the mitochondrial morphology. Though the mitochondrial tubules were largely homogenously stained in the sole confocal image, obvious differences in the length and density of the mitochondria were discovered in the cells after $\mathrm{TiO}_{2}$ NPs treatment. STED was further employed to obtain the images of nanoscale submitochondrial structures of the mitochondria. As the appearance of fluorescence represents the location of the mitochondria, the normalized variance values represented the distribution of mitochondrial fragmentation. The more peak values in the $\mathrm{TiO}_{2} \mathrm{NPs}$-treated group indicated more fragmentation. Other mitochondrial fluorescent stains could be used to label the mitochondria, such as tetramethylrhodamine methyl ester (TMRM) [34],

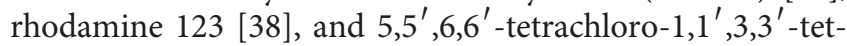
raethylbenzimidazolylcarbocyanine iodide (JC-1) [39]. Here, we only explored the mitochondria itself. It is more persuasive to make a thorough inquiry of mitochondrial proteins, such as mitochondrial translocase of the outer membrane (TOM 20) 


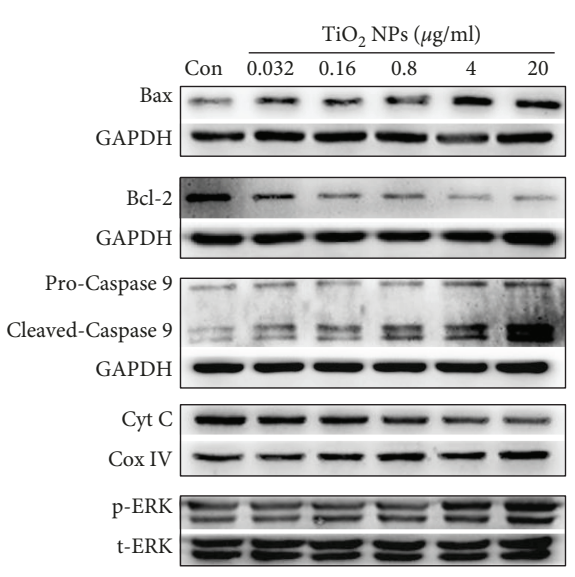

(a)
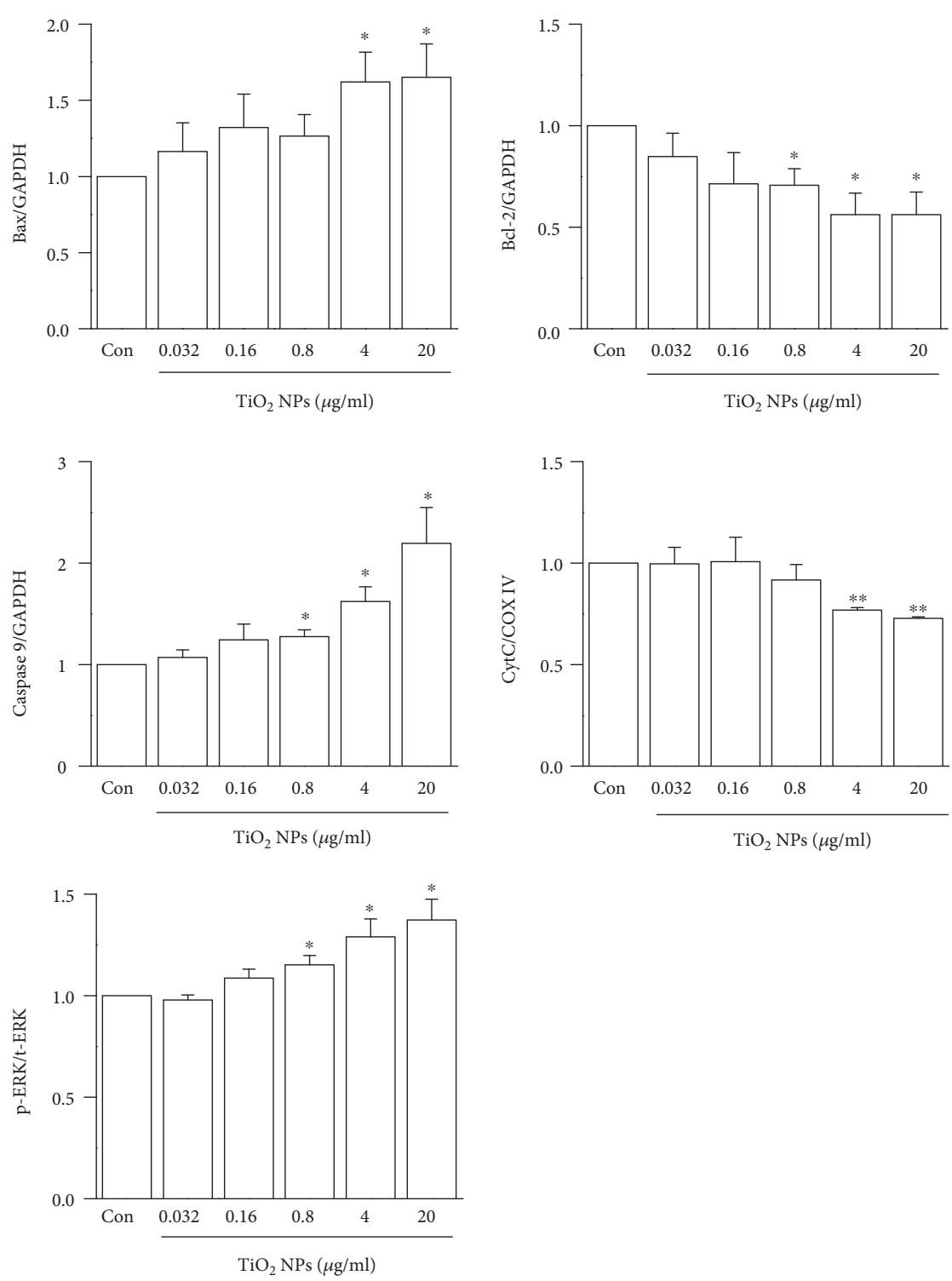

(b)

FIGURE 8: Effects of $\mathrm{TiO}_{2}$ NPs on apoptosis-related proteins. (a) Representative Western blot bands of apoptosis-related proteins in control cells and cells treated with $\mathrm{TiO}_{2} \mathrm{NPs}$ for $24 \mathrm{~h}$. (b) Blot analysis of $\mathrm{TiO}_{2} \mathrm{NPs}$-induced apoptotic protein expressions in HT22 cells $\left({ }^{*} p<0.05\right.$ and $\left.{ }^{* *} p<0.01\right)$. Bax: B-cell lymphoma 2 -associated X protein; Bcl-2: B-cell lymphoma 2; COXIV: cytochrome c oxidase IV; Cyt C: cytochrome c; t-Erk: total extracellular-regulated protein kinases; p-Erk: phosphorylated extracellular-regulated protein kinases; GAPDH: glyceraldehyde-3-phosphate dehydrogenase; ERK1/2: extracellular-regulated protein kinases 1/2.

complex [40], mitochondrial inner membrane organizing system (MINOS) [33], and voltage-dependent anion channel 1 (VDAC1), an outer mitochondrial membrane protein [41]. STED is a novel approach to explore the submitochondrial structures, providing a new method for deep investigations of nanoparticle toxicity in the future.

Keeping a balance of fusion and fission controls mitochondrial morphology and their subcellular location and function [42]. Once the balance is disturbed, it restricts mitochondrial movement, reduces energy production, increases oxidative stress, and promotes cell functional disorder and cell death [23, 43]. Additionally, accumulating evidence indicates that mitochondrial fragmentation resulted from an imbalanced fusion and fission and is associated with abnormal mitochondrial function and cell destruction $[30,31]$. When apoptosis is induced, Drp1 leaves the cytosol and passes to the membrane of mitochondria [44]. In our study, p-Drp1 was increased after $\mathrm{TiO}_{2}$ NPs exposure. Studies have reported that Drp1 has a critical effect on mitochondrial fragmentation, and excessive expression of Drp1 can cause mitochondrial fragmentation, while down expression slows the mitochondrial fragmentation and reduces cell damage $[44,45]$. So, Drp1 plays a vital role in preserving the dynamic balance of mitochondria. In the current study, the change of mitochondrial morphology supports the observation that the expression of fusion/fission proteins was 
altered under $\mathrm{TiO}_{2}$ NPs exposure, as normal control cells showed normal mitochondrial length, while $\mathrm{TiO}_{2} \mathrm{NPs}$ reduced the mitochondrial length. Our results demonstrate that $\mathrm{TiO}_{2}$ NPs affect mitochondrial dynamics via the expression of fusion/fission proteins, leading to mitochondrial fragmentation.

Erk1/2 are widely expressed extracellular-regulated protein kinases that take part in regulating cell proliferation and differentiation, cell morphology maintenance, cytoskeleton construction, cell apoptosis, and cell carcinogenesis. A study has shown significant increases of phospho-ERK in neurodegenerative dopaminergic neurons [46]. The activation of ERK1/2 is involved in mitochondrial dynamic disorder by regulating Drp1 phosphorylation at Ser616 and Drp1 translocation [47]. The inhibition of ERK1/2 phosphorylation can protect mitochondrial morphology and dynamic balance [36]. Here, we explored the possibility of using the ERK protein in mitochondrial dynamic disorder induced by $\mathrm{TiO}_{2}$ NPs. Western blot data demonstrated that the p-ERK expression was significantly increased in cells by high $\mathrm{TiO}_{2} \mathrm{NPs}$ exposure. Maybe, the p-ERK is involved in regulating Drp1 function, and ERK1/2 phosphorylation might promote Drp1 recruitment to mitochondria; then, the ERK-Drp1 signaling pathway could affect the mitochondria through fusion/fission balance to prevent excessive fission procedures.

Oxidative stress is the result of the overaccumulation of ROS and a deficient antioxidant defense [4, 48-50]. Oxidative stress could damage DNA, which could result in the loss of cell viability in the central nervous system [51, 52]. ROS participates in many cellular activities, including cell proliferation, cell growth, and cell apoptosis [53]. $\mathrm{TiO}_{2} \mathrm{NPs}$ treatment caused excessive ROS production and reduced antioxidant defense, resulting in cell death at last. The increased ROS accumulation may reduce the mitochondrial membrane potential [54-56]. Besides, the reduced mitochondrial membrane potential can trigger mitochondrial fragmentation [57]. Emerging evidence suggests that ROS accumulation may cause mitochondrial fragmentation through the alteration of mitochondrial dynamics [58]. Damage to the integrity of mitochondrial morphology leads to ROS accumulation and induces oxidative stress $[59,60]$. Studies have also demonstrated that Drp1 has a vital role in $\mathrm{TiO}_{2}$ NPs-induced ROS accumulation and mitochondrial membrane potential reduction [47]. So, in our study, Drp1 overexpression caused the imbalance of mitochondrial fission/fusion proteins, resulting in mitochondrial fragmentation, which further led to ROS accumulation and MMP collapse. Meanwhile, ROS accumulation and MMP collapse may in turn aggravate mitochondrial fragmentation. This interaction may lead to cell apoptosis under $\mathrm{TiO}_{2}$ NPs exposure.

\section{Conclusions}

In summary, our study demonstrates that $\mathrm{TiO}_{2} \mathrm{NPs}$ exposure induced mitochondrial dynamic imbalance and damaged mitochondrial function, as evidenced by increased ROS production and reduced mitochondrial membrane potential and mitochondrial ATP production. This observation was accompanied by the increased cell apoptosis under $\mathrm{TiO}_{2}$ NPs insult. These cellular events can be largely prevented via cell incubation with mitoTEMPO. Our findings demonstrate the effects of $\mathrm{TiO}_{2} \mathrm{NPs}$ on mitochondrial dynamics and partly illustrate the underlying mechanisms of $\mathrm{TiO}_{2}$ NPs cytotoxicity.

\section{Data Availability}

The data used to support the findings of this study are available from the corresponding authors upon request.

\section{Conflicts of Interest}

The authors report no conflicts of interest in this work.

\section{Acknowledgments}

This work was supported by the National Natural Science Foundation of China (Grants 81870723, 81570915, and 81371503) and the National Basic Research Program of China (Grants 2012CB932502 and 2011CB504506).

\section{Supplementary Materials}

Supplementary 1. Supplementary Figure 1: mitoTEMPO reverses mitochondrial fragmentation caused by $\mathrm{TiO}_{2} \mathrm{NPs}$ exposure in HT22 cells. (A) Representative confocal images of mitochondria. (B) The average length of the mitochondria in entire cells and quantification of the size of mitochondria according to the grouped differently sized bins. $n=5$ cells/group. ( ${ }^{* *} p<0.01$ vs. the control group and ${ }^{\#} p<0.05$ vs. the $\mathrm{TiO}_{2}$ NPs group.)

Supplementary 2. Supplementary Figure 2: mitoTEMPO reverses mitochondrial fragmentation caused by $\mathrm{TiO}_{2} \mathrm{NPs}$ exposure in BE2C cells. (A) Representative confocal images of mitochondria. (B) The average length of the mitochondria in entire cells and quantification of the size of mitochondria according to the grouped differently sized bins. $n=7$ cells/group. ( ${ }^{* *} p<0.01$ vs. the control group and ${ }^{\# \#} p<0.01$ vs. the $\mathrm{TiO}_{2}$ NPs group.)

Supplementary 3. Supplementary Figure 3: mitoTEMPO largely prevents the imbalanced expression of Drp1 and Opal caused by $\mathrm{TiO}_{2}$ NPs exposure in HT22 cells. (A) Representative Western blot bands of Drp1 and Opa1 from mitochondrial and cytoplasmic proteins. (B) The quantification of the expressions of Drp1 and Opa1 from mitochondrial and cytoplasmic proteins. $\left({ }^{* *} p<0.01\right.$ vs. the control group and ${ }^{\#} p<0.05$ vs. the $\mathrm{TiO}_{2}$ NPs group.) Drp1: dynamin-related protein 1; Opa1: optic atrophy 1; COXIV: cytochrome c oxidase IV; GAPDH: glyceraldehyde-3phosphate dehydrogenase.

Supplementary 4. Supplementary Figure 4: mitoTEMPO reverses oxidative stress, mitochondrial membrane potential, and the production of ATP caused by $\mathrm{TiO}_{2}$ NPs treatment in HT22 cells. (A) ROS levels, (B) MDA levels, (C) GSH levels, (D) MMP, (E) ATP production, and (F) MitoSOX Red intensity $\left({ }^{*} p<0.05\right.$ vs. the control group, ${ }^{* *} p<0.01$ vs. the control 
group, ${ }^{\#} p<0.05$ vs. the $\mathrm{TiO}_{2} \mathrm{NPs}$ group, and ${ }^{\# \#} p<0.01$ vs. the $\mathrm{TiO}_{2}$ NPs group.) ROS: reactive oxygen species; MDA: malondialdehyde; GSH: reduced glutathione hormone; MMP: mitochondrial membrane potential; ATP: adenosine triphosphate.

Supplementary 5. Supplementary Figure 5: mitoTEMPO suppresses $\mathrm{TiO}_{2}$ NPs-induced mitochondrial superoxide production in BE2C cells. (A) Representative images of MitoSOX Red (red) and Hoechst 33342 (blue) staining. (B) The statistics of the fluorescence intensity. (C) The fluorescence intensity of MitoSOX Red using an automated microplate spectrophotometer. $\left({ }^{* *} p<0.01 \quad\right.$ vs. the control group, ${ }^{\#} p<0.05$ vs. the $\mathrm{TiO}_{2} \mathrm{NPs}$ group, and ${ }^{\# \#} p<0.01$ vs. the $\mathrm{TiO}_{2}$ NPs group.)

Supplementary 6. Supplementary Figure 6: mitoTEMPO reverses the ratio of PI-positive cells in HT22 cells by Hoechst 33342/PI staining. (A) Typical fluorescence microscopy images of the control group, $\mathrm{TiO}_{2} \mathrm{NPs}$ group, $\mathrm{TiO}_{2} \mathrm{NPs}$ +mitoTEMPO group, and mitoTEMPO group. Upper row: Hoechst 33342 (red); middle row: PI (blue); bottom row: merged. (B) The proportion of PI-positive cells treated with $\mathrm{TiO}_{2}$ NPs for $24 \mathrm{~h}$. ${ }^{* *} p<0.01$ vs. the control group and $\#$ \# $p<0.01$ vs. the $\mathrm{TiO}_{2}$ NPs group.)

Supplementary 7. Supplementary Figure 7: mitoTEMPO reverses the ratio of PI-positive cells in $\mathrm{BE} 2 \mathrm{C}$ cells by Hoechst 33342/PI staining. (A) Typical fluorescence microscopy images of the control group, $\mathrm{TiO}_{2} \mathrm{NPs}$ group, $\mathrm{TiO}_{2} \mathrm{NPs}$ + mitoTEMPO group, and mitoTEMPO group. Upper row: Hoechst 33342 (red); middle row: PI (blue); bottom row: merged. (B) The proportion of PI-positive cells treated with $\mathrm{TiO}_{2}$ NPs for $24 \mathrm{~h}$. ( ${ }^{* *} p<0.01$ vs. the control group and $\#$ \# $p<0.01$ vs. the $\mathrm{TiO}_{2}$ NPs group.)

Supplementary 8. Supplementary Figure 8: mitoTEMPO prevents the changes of apoptosis-related proteins caused by $\mathrm{TiO}_{2} \mathrm{NPs}_{\text {in }} \mathrm{HT} 22$ cells. (A) Representative Western blotbands of apoptosis-related proteins. (B) Blot analysis of apoptotic protein expressions in HT22 cells. $\left({ }^{*} p<0.05\right.$ vs. the control group, ${ }^{* *} p<0.01$ vs. the control group, and ${ }^{\#} p<0.05$ vs. the $\mathrm{TiO}_{2}$ NPs group.) Bax: B-cell lymphoma 2-associated X protein; Bcl-2: B-cell lymphoma 2; COXIV: cytochrome c oxidase IV; Cyt C: cytochrome c; t-Erk: total extracellular-regulated protein kinases; p-Erk: phosphorylated extracellular-regulated protein kinases; GAPDH: glyceraldehyde-3-phosphate dehydrogenase; ERK1/2: extracellular-regulated protein kinases 1/2.

\section{References}

[1] H. Choi, E. Stathatos, and D. D. Dionysiou, "Sol-gel preparation of mesoporous photocatalytic $\mathrm{TiO}_{2}$ films and $\mathrm{TiO}_{2} / \mathrm{Al}_{2} \mathrm{O}_{3}$ composite membranes for environmental applications," Applied Catalysis B: Environmental, vol. 63, no. 1-2, pp. 6067, 2006.

[2] C. R. Esterkin, A. C. Negro, O. M. Alfano, and A. E. Cassano, "Air pollution remediation in a fixed bed photocatalytic reactor coated with $\mathrm{TiO}_{2}$," AICHE Journal, vol. 51, no. 8, pp. 2298-2310, 2005.
[3] T. Kaida, K. Kobayashi, M. Adachi, and F. Suzuki, "Optical characteristics of titanium oxide interference film and the film laminated with oxides and their applications for cosmetics," Journal of Cosmetic Science, vol. 55, no. 2, pp. 219-220, 2004.

[4] T. C. Long, N. Saleh, R. D. Tilton, G. V. Lowry, and B. Veronesi, "Titanium dioxide (P25) produces reactive oxygen species in immortalized brain microglia (BV2): implications for nanoparticle neurotoxicity," Environmental Science \& Technology, vol. 40, no. 14, pp. 4346-4352, 2006.

[5] T. Xia, M. Kovochich, and A. Nel, "The role of reactive oxygen species and oxidative stress in mediating particulate matter injury," Clinics in Occupational and Environmental Medicine, vol. 5, no. 4, pp. 817-836, 2006.

[6] N. C. Mueller and B. Nowack, "Exposure modeling of engineered nanoparticles in the environment," Environmental Science \& Technology, vol. 42, no. 12, pp. 4447-4453, 2008.

[7] C. O. Robichaud, A. E. Uyar, M. R. Darby, L. G. Zucker, and M. R. Wiesner, "Estimates of upper bounds and trends in nano- $\mathrm{TiO}_{2}$ production as a basis for exposure assessment," Environmental Science \& Technology, vol. 43, no. 12, pp. 4227-4233, 2009.

[8] N. A. Patil, W. N. Gade, and D. D. Deobagkar, "Epigenetic modulation upon exposure of lung fibroblasts to $\mathrm{TiO}_{2}$ and $\mathrm{ZnO}$ nanoparticles: alterations in DNA methylation," International Journal of Nanomedicine, vol. 11, pp. 4509-4519, 2016.

[9] L. Zhang, X. Xie, Y. Zhou et al., "Gestational exposure to titanium dioxide nanoparticles impairs the placentation through dysregulation of vascularization, proliferation and apoptosis in mice," International Journal of Nanomedicine, vol. 13, pp. 777-789, 2018.

[10] J. Wang, G. Zhou, C. Chen et al., “Acute toxicity and biodistribution of different sized titanium dioxide particles in mice after oral administration," Toxicology Letters, vol. 168, no. 2, pp. 176-185, 2007.

[11] J. Wang, Y. Liu, F. Jiao et al., "Time-dependent translocation and potential impairment on central nervous system by intranasally instilled $\mathrm{TiO}_{2}$ nanoparticles," Toxicology, vol. 254, no. 1-2, pp. 82-90, 2008.

[12] J. X. Wang, C. Y. Chen, H. W. Yu et al., "Distribution of $\mathrm{TiO}_{2}$ particles in the olfactory bulb of mice after nasal inhalation using microbeam SRXRF mapping techniques," Journal of Radioanalytical and Nuclear Chemistry, vol. 272, no. 3, pp. 527-531, 2007.

[13] J. Wang, C. Chen, Y. Liu et al., "Potential neurological lesion after nasal instillation of $\mathrm{TiO}_{2}$ nanoparticles in the anatase and rutile crystal phases," Toxicology Letters, vol. 183, no. 1-3, pp. 72-80, 2008.

[14] J. Wu, W. Liu, C. Xue et al., “Toxicity and penetration of $\mathrm{TiO}_{2}$ nanoparticles in hairless mice and porcine skin after subchronic dermal exposure," Toxicology Letters, vol. 191, no. 1, pp. 1-8, 2009.

[15] X. Gao, S. Yin, M. Tang et al., "Effects of developmental exposure to $\mathrm{TiO}_{2}$ nanoparticles on synaptic plasticity in hippocampal dentate gyrus area: an in vivo study in anesthetized rats," Biological Trace Element Research, vol. 143, no. 3, pp. 16161628, 2011.

[16] A. Nel, T. Xia, L. Madler, and N. Li, "Toxic potential of materials at the nanolevel," Science, vol. 311, no. 5761, pp. 622-627, 2006.

[17] T. Xia, M. Kovochich, J. Brant et al., "Comparison of the abilities of ambient and manufactured nanoparticles to induce 
cellular toxicity according to an oxidative stress paradigm," Nano Letters, vol. 6, no. 8, pp. 1794-1807, 2006.

[18] H. L. Liang, F. Sedlic, Z. Bosnjak, and V. Nilakantan, "SOD1 and MitoTEMPO partially prevent mitochondrial permeability transition pore opening, necrosis, and mitochondrial apoptosis after ATP depletion recovery," Free Radical Biology \& Medicine, vol. 49, no. 10, pp. 1550-1560, 2010.

[19] H. Hu and M. Li, "Mitochondria-targeted antioxidant mitotempo protects mitochondrial function against amyloid beta toxicity in primary cultured mouse neurons," Biochemical and Biophysical Research Communications, vol. 478, no. 1, pp. 174-180, 2016.

[20] D. C. Chan, "Mitochondrial fusion and fission in mammals," Annual Review of Cell and Developmental Biology, vol. 22, no. 1, pp. 79-99, 2006.

[21] C. Delettre, G. Lenaers, J. M. Griffoin et al., "Nuclear gene OPA1, encoding a mitochondrial dynamin-related protein, is mutated in dominant optic atrophy," Nature Genetics, vol. 26, no. 2, pp. 207-210, 2000.

[22] T. Koshiba, S. A. Detmer, J. T. Kaiser, H. Chen, J. McCaffery, and D. C. Chan, "Structural basis of mitochondrial tethering by mitofusin complexes," Science, vol. 305, no. 5685, pp. 858-862, 2004.

[23] I. Scott and R. J. Youle, "Mitochondrial fission and fusion," Essays in Biochemistry, vol. 47, pp. 85-98, 2010.

[24] D. C. Chan, "Mitochondria: dynamic organelles in disease, aging, and development," Cell, vol. 125, no. 7, pp. 12411252, 2006.

[25] E. Smirnova, L. Griparic, D. L. Shurland, and A. M. van der Bliek, "Dynamin-related protein Drp1 is required for mitochondrial division in mammalian cells," Molecular Biology of the Cell, vol. 12, no. 8, pp. 2245-2256, 2001.

[26] Y. Yoon, E. W. Krueger, B. J. Oswald, and M. A. McNiven, "The mitochondrial protein hFis1 regulates mitochondrial fission in mammalian cells through an interaction with the dynamin-like protein DLP1," Molecular and Cellular Biology, vol. 23, no. 15, pp. 5409-5420, 2003.

[27] H. Otera, C. Wang, M. M. Cleland et al., "Mff is an essential factor for mitochondrial recruitment of Drp1 during mitochondrial fission in mammalian cells," The Journal of Cell Biology, vol. 191, no. 6, pp. 1141-1158, 2010.

[28] C. S. Palmer, L. D. Osellame, D. Laine, O. S. Koutsopoulos, A. E. Frazier, and M. T. Ryan, "MiD49 and MiD51, new components of the mitochondrial fission machinery," $E M B O$ Reports, vol. 12, no. 6, pp. 565-573, 2011.

[29] J. Zhao, T. Liu, S. Jin et al., "Human MIEF1 recruits Drp1 to mitochondrial outer membranes and promotes mitochondrial fusion rather than fission," The EMBO Journal, vol. 30, no. 14, pp. 2762-2778, 2011.

[30] J. Grohm, N. Plesnila, and C. Culmsee, "Bid mediates fission, membrane permeabilization and peri-nuclear accumulation of mitochondria as a prerequisite for oxidative neuronal cell death," Brain, Behavior, and Immunity, vol. 24, no. 5, pp. 831-838, 2010.

[31] J. Estaquier and D. Arnoult, "Inhibiting Drp1-mediated mitochondrial fission selectively prevents the release of cytochrome c during apoptosis," Cell Death and Differentiation, vol. 14, no. 6, pp. 1086-1094, 2007.

[32] J. Liu, L. Li, and W. Z. Suo, "HT22 hippocampal neuronal cell line possesses functional cholinergic properties," Life Sciences, vol. 84, no. 9-10, pp. 267-271, 2009.
[33] D. C. Jans, C. A. Wurm, D. Riedel et al., "STED superresolution microscopy reveals an array of MINOS clusters along human mitochondria," Proceedings of the National Academy of Sciences of the United States of America, vol. 110, no. 22, pp. 8936-8941, 2013.

[34] M. Ishigaki, M. Iketani, M. Sugaya et al., "STED superresolution imaging of mitochondria labeled with TMRM in living cells," Mitochondrion, vol. 28, pp. 79-87, 2016.

[35] H. Shi, R. Magaye, V. Castranova, and J. Zhao, "Titanium dioxide nanoparticles: a review of current toxicological data," Particle and Fibre Toxicology, vol. 10, no. 1, p. 15, 2013.

[36] X. Gan, S. Huang, L. Wu et al., "Inhibition of ERK-DLP1 signaling and mitochondrial division alleviates mitochondrial dysfunction in Alzheimer's disease cybrid cell," Biochimica et Biophysica Acta (BBA) - Molecular Basis of Disease, vol. 1842, no. 2, pp. 220-231, 2014.

[37] S. Hussain, L. C. Thomassen, I. Ferecatu et al., "Carbon black and titanium dioxide nanoparticles elicit distinct apoptotic pathways in bronchial epithelial cells," Particle and Fibre Toxicology, vol. 7, no. 1, p. 10, 2010.

[38] M. K. Miah, I. H. Shaik, U. Bickel, and R. Mehvar, "Effects of hepatic ischemia-reperfusion injury on the P-glycoprotein activity at the liver canalicular membrane and blood-brain barrier determined by in vivo administration of rhodamine 123 in rats," Pharmaceutical Research, vol. 31, no. 4, pp. 861-873, 2014.

[39] B. Chazotte, "Labeling mitochondria with JC-1," Cold Spring Harbor Protocols, vol. 2011, no. 9, 2011.

[40] C. A. Wurm, D. Neumann, M. A. Lauterbach et al., "Nanoscale distribution of mitochondrial import receptor Tom20 is adjusted to cellular conditions and exhibits an inner-cellular gradient," Proceedings of the National Academy of Sciences of the United States of America, vol. 108, no. 33, pp. 1354613551, 2011.

[41] H. Singh, R. Lu, P. F. G. Rodríguez et al., "Visualization and quantification of cardiac mitochondrial protein clusters with STED microscopy," Mitochondrion, vol. 12, no. 2, pp. 230236, 2012.

[42] L. M. Westrate, J. A. Drocco, K. R. Martin, W. S. Hlavacek, and J. P. MacKeigan, "Mitochondrial morphological features are associated with fission and fusion events," PLoS One, vol. 9, no. 4, article e95265, 2014.

[43] A. Jahani-Asl, M. Germain, and R. S. Slack, "Mitochondria: joining forces to thwart cell death," Biochimica et Biophysica Acta (BBA) - Molecular Basis of Disease, vol. 1802, no. 1, pp. 162-166, 2010.

[44] K. W. Young, L. G. P. Piñon, E. T. W. Bampton, and P. Nicotera, "Different pathways lead to mitochondrial fragmentation during apoptotic and excitotoxic cell death in primary neurons," Journal of Biochemical and Molecular Toxicology, vol. 24, no. 5, pp. 335-341, 2010.

[45] S. Frank, B. Gaume, E. S. Bergmann-Leitner et al., "The role of dynamin-related protein 1, a mediator of mitochondrial fission, in apoptosis," Developmental Cell, vol. 1, no. 4, pp. 515$525,2001$.

[46] J. H. Zhu, F. Guo, J. Shelburne, S. Watkins, and C. T. Chu, "Localization of phosphorylated ERK/MAP kinases to mitochondria and autophagosomes in Lewy body diseases," Brain Pathology, vol. 13, no. 4, pp. 473-481, 2003.

[47] Y. X. Gui, X. Y. Wang, W. Y. Kang et al., "Extracellular signalregulated kinase is involved in alpha-synuclein-induced 
mitochondrial dynamic disorders by regulating dynamin-like protein 1," Neurobiology of Aging, vol. 33, no. 12, pp. 28412854, 2012.

[48] E. Huerta-García, J. A. Pérez-Arizti, S. G. Márquez-Ramírez et al., "Titanium dioxide nanoparticles induce strong oxidative stress and mitochondrial damage in glial cells," Free Radical Biology and Medicine, vol. 73, pp. 84-94, 2014.

[49] I. Iavicoli, V. Leso, L. Fontana, and A. Bergamaschi, "Toxicological effects of titanium dioxide nanoparticles: a review of in vitro mammalian studies," European Review for Medical and Pharmacological Sciences, vol. 15, no. 5, pp. 481-508, 2011.

[50] J. J. Stevens, B. Graham, E. Dugo, B. Berhaneselassie-Sumner, K. Ndebele, and P. B. Tchounwou, "Arsenic trioxide induces apoptosis via specific signaling pathways in HT-29 colon cancer cells," Journal of Cancer Science \& Therapy, vol. 9, no. 1, pp. 298-306, 2017.

[51] J. A. Smith, S. Park, J. S. Krause, and N. L. Banik, "Oxidative stress, DNA damage, and the telomeric complex as therapeutic targets in acute neurodegeneration," Neurochemistry International, vol. 62, no. 5, pp. 764-775, 2013.

[52] V. Freyre-Fonseca, N. L. Delgado-Buenrostro, E. B. GutiérrezCirlos et al., "Titanium dioxide nanoparticles impair lung mitochondrial function," Toxicology Letters, vol. 202, no. 2, pp. 111-119, 2011.

[53] B. Halliwell and J. M. Gutteridge, "Oxygen toxicity, oxygen radicals, transition metals and disease," Biochemical Journal, vol. 219, no. 1, pp. 1-14, 1984.

[54] Y. Liu and D. R. Schubert, "The specificity of neuroprotection by antioxidants," Journal of Biomedical Science, vol. 16, no. 1, p. 98, 2009.

[55] Y. Sagara, K. Ishige, C. Tsai, and P. Maher, "Tyrphostins protect neuronal cells from oxidative stress," The Journal of Biological Chemistry, vol. 277, no. 39, pp. 36204-36215, 2002.

[56] S. Kumari, S. L. Mehta, and P. A. Li, "Glutamate induces mitochondrial dynamic imbalance and autophagy activation: preventive effects of selenium," PLoS One, vol. 7, no. 6, article e39382, 2012.

[57] G. Benard, N. Bellance, D. James et al., "Mitochondrial bioenergetics and structural network organization," Journal of Cell Science, vol. 120, no. 5, Part 5, pp. 838-848, 2007.

[58] S. Wu, F. Zhou, Z. Zhang, and D. Xing, "Mitochondrial oxidative stress causes mitochondrial fragmentation via differential modulation of mitochondrial fission-fusion proteins," The FEBS Journal, vol. 278, no. 6, pp. 941-954, 2011.

[59] C. Mammucari and R. Rizzuto, "Signaling pathways in mitochondrial dysfunction and aging," Mechanisms of Ageing and Development, vol. 131, no. 7-8, pp. 536-543, 2010.

[60] A. M. van der Bliek, Q. Shen, and S. Kawajiri, "Mechanisms of mitochondrial fission and fusion," Cold Spring Harbor Perspectives in Biology, vol. 5, no. 6, 2013. 


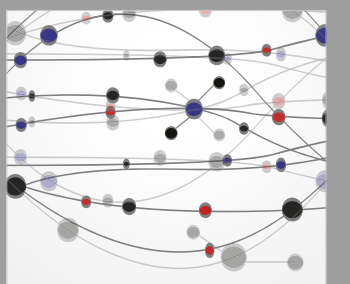

The Scientific World Journal
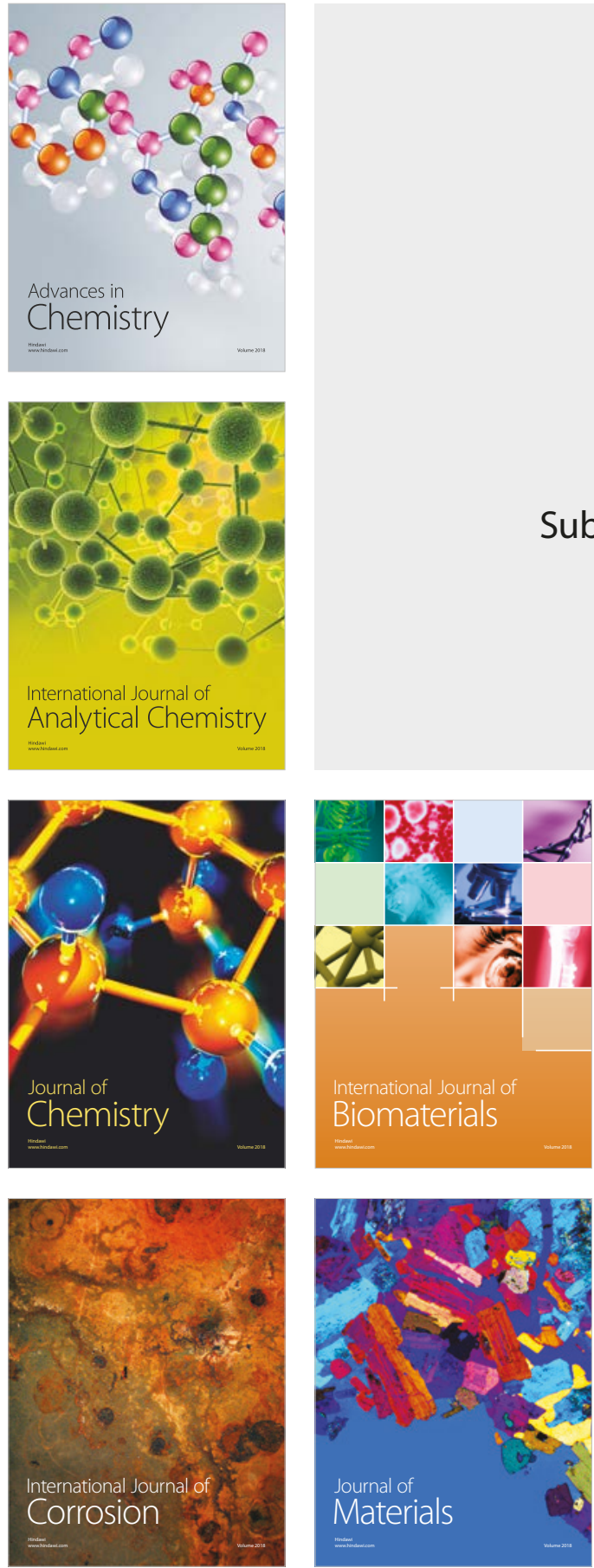

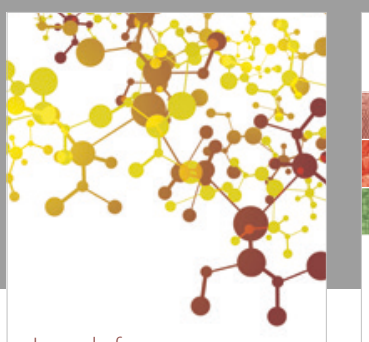

Journal of

Applied Chemistry
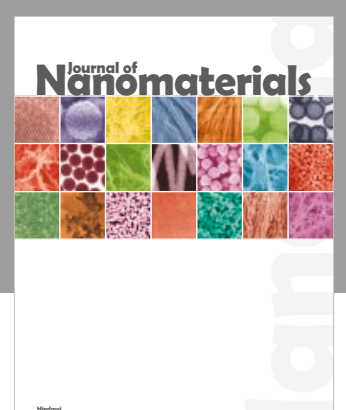

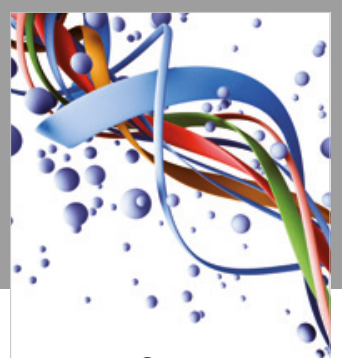

Scientifica

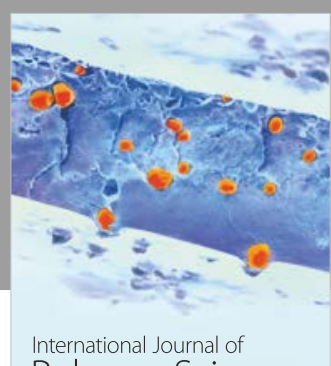

Polymer Science

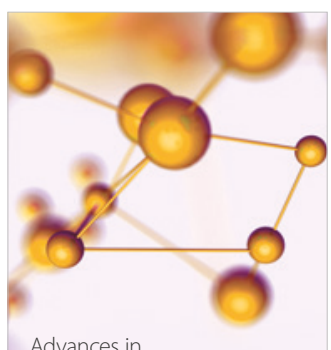

Physical Chemistry
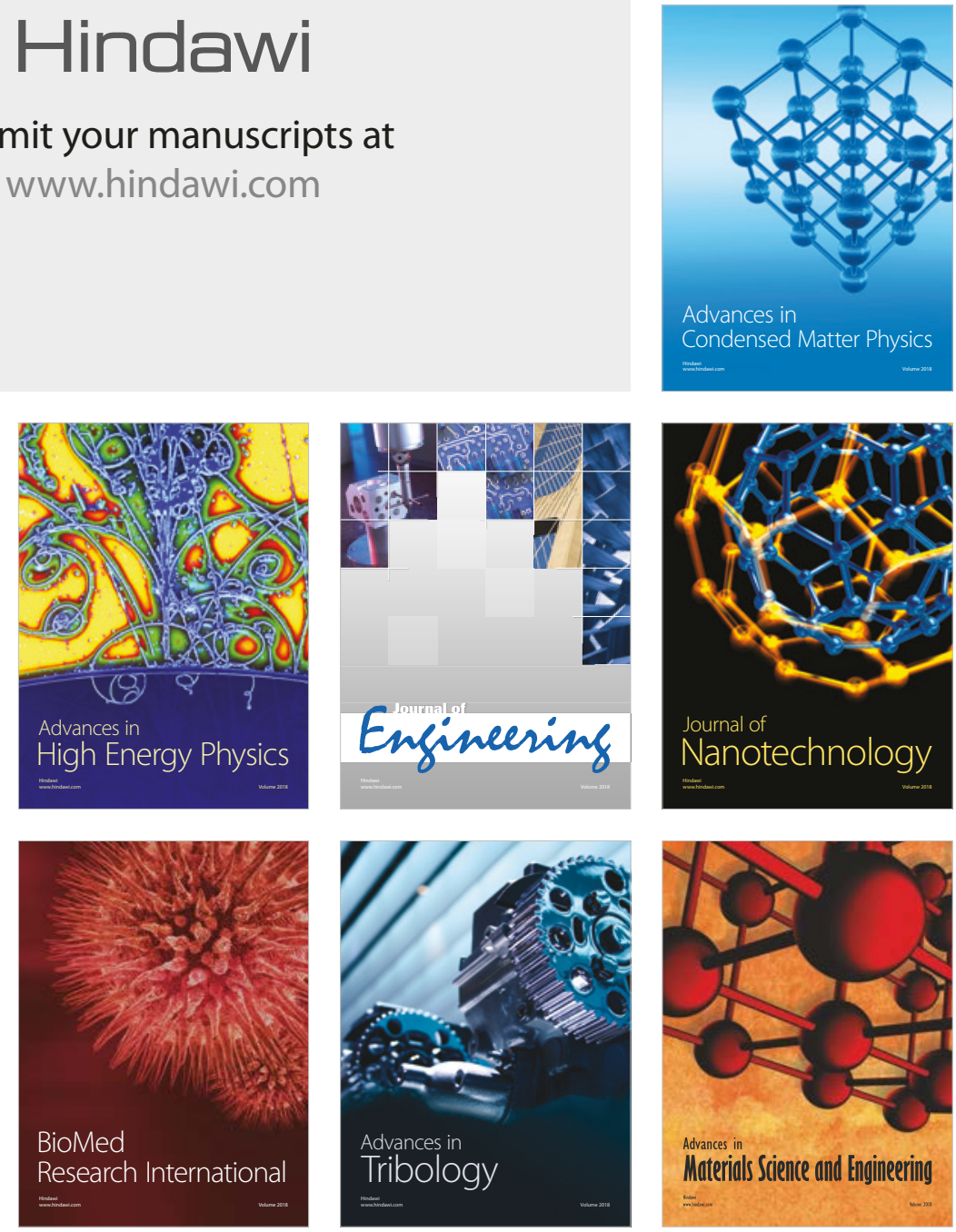